\title{
Ectoparasites des animaux : méthodes de lutte écologique, biologique, génétique et mécanique
}

\author{
D. CUISANCE *, N. BARRÉ ** et R. DE DEKEN ***
}

\begin{abstract}
Résumé : Même si l'emploi des insecticides demeure le moyen de base pour lutter contre la plupart des ectoparasites, diverses méthodes se développent pour agir en complément ou en synergie de ces produits, afin d'accroître leur efficacité et de réduire leurs effets indésirables en obtenant des stratégies écologiquement acceptables.
\end{abstract}

Ces méthodes ont été classées en lutte écologique (modification du milieu de vie du parasite), lutte biologique (prédation, parasitisme, pathogènes, etc.), lutte génétique (lâchers de mâles stériles, hybridation, manipulations génétiques), et lutte mécanique (piégeage, utilisation de répulsifs).

Leur application dépend des particularités biologiques et écologiques de l'ectoparasite permettant d'agir directement ou indirectement sur sa mortalité et/ou sa natalité. Les auteurs passent en revue les principales méthodes applicables pour les grands groupes d'ectoparasites d'intérêt vétérinaire.

Les méthodes non chimiques donnent lieu à des recherches diverses et prometteuses, en particulier grâce aux biotechnologies récentes.

MOTS-CLÉS : Ectoparasites - Lutte biologique - Lutte écologique - Lutte génétique - Lutte mécanique - Méthodes de lutte.

\section{INTRODUCTION}

Même si les insecticides demeurent les moyens de lutte contre les ectoparasites des animaux actuellement les plus utilisés du fait de leur efficacité, de leur coût et de leur facilité d'emploi, d'autres techniques de lutte non chimiques, offensives ou défensives, sont expérimentées et quelques-unes sont actuellement appliquées. Ces méthodes ont pour objet d'empêcher le développement de l'insecte ou de l'acarien par une action directe ou indirecte sur sa natalité ou sa mortalité sans faire appel aux insecticides :

- soit en modifiant son biotope (végétation, hôtes nourriciers, etc.), et l'on parle alors de lutte écologique ;

\footnotetext{
* Centre de coopération internationale en recherche agronomique pour le développement, Département d'élevage et de médecine vétérinaire (CIRAD/EMVT), 911, avenue Agropolis, B.P. 5045, 34032 Montpellier Cedex 1, France.

** Centre de coopération internationale en recherche agronomique pour le développement, Département d'élevage et de médecine vétérinaire (CIRAD/EMVT), B.P. 1232, 97185 Pointe-à-Pitre Cedex, Guadeloupe.

*** Institut de médecine tropicale, Département Santé animale, Nationalestraat 155, B-2000 Anvers, Belgique.
} 
- soit en l'exposant à des prédateurs, des parasites, des parasitoïdes ou des germes pathogènes, ou en perturbant des mécanismes physiologiques fondamentaux (synthèse de la chitine, des vitamines, diurèse, etc.) ; ces modalités constituent la lutte biologique;

- soit en altérant ou en modifiant le potentiel reproducteur de l'insecte : il s'agit alors de lutte génétique ;

- soit en soumettant l'insecte à l'action de moyens artificiels de capture ou d'évitement du contact avec l'hôte : c'est la lutte mécanique.

Les possibilités d'exploiter les réponses immunologiques de l'hôte ne seront pas exposées ici.

L'application de ces différentes méthodes dépend de nombreux facteurs biologiques propres à chaque espèce, en particulier des processus d'autorégulation dépendant de la densité ou de facteurs non biologiques (climatiques, par exemple).

\section{MYIASES}

La mise au point de méthodes de lutte, autres que par insecticides, s'est surtout développée vis-à-vis des myiases primaires (ou obligatoires), et essentiellement celles des plaies, qui causent les plus grandes pertes économiques, tout principalement la myiase occasionnée par la lucilie bouchère (Cochlyomyia hominivorax) (54).

\section{COCHLYOMYIA HOMINIVORAX}

La maîtrise de ce fléau dépend de l'application conjointe de mesures de lutte contre l'insecte et de mesures préventives: Celles-ci reposent sur la surveillance et le traitement de toutes blessures ouvertes sur les animaux hôtes potentiels en vue d'arrêter le cycle de développement de l'insecte au niveau larvaire et de rendre moins attirantes les blessures pour empêcher une infestation.

Ces traitements sont à base d'insecticides (coumaphos essentiellement) à fort pouvoir larvicide et insecticide.

\section{Lutte écologique}

La lutte écologique consiste à éviter toutes les conditions ou situations aboutissant à l'apparition de plaies, milieu favorable et obligatoire au développement des larves et attractif pour les adultes. Il faut donc:

- éviter les zones à végétation épineuse, les clôtures vulnérantes ;

- éviter toutes interventions obstétricales ou chirurgicales (castration, caudectomie, marquage au fer, écornage, etc.), pendant les saisons à risques (surtout les saisons chaudes et humides);

- gérer l'exploitation des pâturages en fonction des zones infestées (éloignement ou pâture de nuit);

- limiter les populations d'ectoparasites vulnérants (tiques en particulier);

- détruire les cadavres ou les enterrer.

Toutes ces mesures doivent être associées à des mesures sérieuses de quarantaine et à une stricte surveillance des mouvements d'animaux (voies terrestre, maritime et aéricnne) 
entre les zones d'un même pays et entre les pays voisins, reposant sur des inspections intensives, qui conditionnent le succès des techniques de lutte mises en place $(53,54)$.

\section{Lutte biologique}

Aucun moyen de lutte biologique n'est actuellement disponible sur le terrain.

\section{Lutte génétique}

La technique des lâchers massifs de mâles stériles, proposée par Knipling dès 1937, est le premier moyen de lutte génétique utilisé à vaste échelle dans la lutte contre un insecte. Elle a été appliquée sous forme d'un projet pionnier ambitieux et réussi, d'abord sur le continent américain (134), puis récemment en Libye (37).

Cette méthode de lutte a été retenue malgré le coût important de la mise en place d'élevages en masse de l'insecte, car elle apparaissait comme le seul moyen d'éradiquer la lucilie de certains pays avec une haute rentabilité en regard des pertes infligées au bétail et à la faune sauvage. Elle n'est pas utilisée seule, mais en association étroite avec des mesures d'inspection, de surveillance et de traitements des plaies.

Elle s'applique bien à Cochlyomyia hominivorax car la femelle de cette espèce ne s'accouple en général qu'une fois dans sa vie. L'élevage est bien maîtrisé (11).

Le principe de cette technique est de lâcher sur un mode inondatif (rapport de dix mâles stérilisés pour un mâle sauvage) des mâles stérilisés par rayons gamma qui, par insémination des jeunes femelles, vont entraîner progressivement une réduction de la reproduction pouvant aller jusqu'à l'extinction de l'espèce.

L'élevage de l'insecte s'est fait dans deux « usines », dont une seule est actuellement opérationnelle. Il s'agit d'une installation de $18900 \mathrm{~m}^{2}$ à Tuxtla Gutiérrez, au sud du Mexique (Commission conjointe Mexique - Etats-Unis d'Amérique pour l'éradication de la lucilie bouchère). La mise au point d'un régime alimentaire gélifié (sang de bovin, lait, œufs, formaldéhyde, eau) permet le développement des différents stades larvaires jusqu'au stade pupal en l'absence d'hôtes vivants. La modernisation des équipements et l'automatisation des techniques permettent de produire jusqu'à 550 millions de pupes par semaine (100 tonnes d'aliments) tout en assurant la qualité des insectes (taux d'émergence, vol, poids, mortalité, compétitivité) et la sécurité (mesures contre les évasions accidentelles).

L'irradiation se fait au stade pupal par irradiation gamma (césium 137), à la dose de 80 Gy délivrée en 1,52 min et provoque des lésions des chromosomes des spermatozoïdes. Le transport des pupes irradiées se fait, soit au sol par camions réfrigérés $\left(10^{\circ} \mathrm{C}\right)$, soit par avion jusqu'à des centres de distribution où les adultes éclosent et sont maintenus en léthargie par refroidissement jusqu'au lâcher.

Celui-ci se fait au sol ou par avion à basse altitude avec des boîtes de carton (contenant jusqu'à 2000 mouches) à un niveau de 300 à 3800 insectes stériles par kilomètre carré dans les zones où les mâles seront en contact immédiat avec les femelles. Le rythme des lâchers est hebdomadaire et, selon les conditions climatiques locales, les lâchers se font juste après les fortes chutes naturelles de densité qui sont fonction des saisons (après la saison froide).

Linvasion de mouches « sauvages » ou l'introduction d'un animal malade compromettent rapidement le succès de la technique, ce qui implique un contrôle strict et une surveillance rigoureuse des troupeaux et la mise en place de barrières de protection renforcée éventuellement par des lâchers inondatifs de mâles stériles (barrière «biologique »). 
Après les premiers essais réussis d'application de la technique sur l'île de Sanibel au large de la Floride en 1953 puis sur l'île de Curaçao (Antilles néerlandaises) par les chercheurs du Département de l'agriculture des Etats-Unis d'Amérique (USDA) en 1954 (134), la méthode fut appliquée au sud-est des Etats-Unis d'Amérique $\left(5000 \mathrm{~km}^{2}\right)$ pour aboutir à l'éradication en 1959, puis au sud-ouest en 1962 afin de prévenir les réinvasions originaires du Mexique. Ces campagnes étaient accompagnées d'une forte participation des éleveurs et des vétérinaires (surveillance, quarantaine, etc.). Le programme s'est étendu à l'Arizona (1964) et à la Californie (1965), avec des lâchers sur une bande de $3200 \mathrm{~km}$ de long, du Pacifique au Golfe du Mexique (155 millions de mouches lâchées par semaine). Le succès fut mitigé à cause de réinvasions sporadiques et de conditions climatiques favorables à l'insecte au Texas (1971-1972). Les Etats-Unis d'Amérique signèrent un accord avec le Mexique pour un programme conjoint de lutte et en particulier la construction d'une usine de mâles stériles au Mexique (200 millions par semaine de 1972 à 1975) qui permettra « d'inonder» les îles de Porto Rico, Mona, Culebra, Vieques et le sud des Etats-Unis d'Amérique. En 1976, la production de l'usine du Texas et celle du sud du Mexique, qui a été accrue pour atteindre plus de 300 millions de mâles par semaine, ont couvert le sud-ouest des Etats-Unis d'Amérique et le nord du Mexique, aboutissant à l'éradication de la lucilie bouchère des Etats-Unis d'Amérique (1982) et à la fermeture de l'usine du Texas.

La campagne s'intensifiera au Mexique (550 millions de mâles lâchés par semaine) en association avec le contrôle, la surveillance et le traitement insecticide des animaux, conduisant à l'élimination de la myiase (1984) au nord de l'isthme de Tehuantepec et à l'établissement d'une barrière de mâles stériles. Actuellement, presque tout le Mexique est libéré et l'incidence au Guatemala et à Belize est fortement réduite (134).

En 1988, l'Afrique du Nord a été accidentellement infestée par la lucilie bouchère en Libye sur $25000 \mathrm{~km}^{2}$. Au début de l'année 1991, sous les auspices de l'Organisation des Nations Unies pour l'alimentation et l'agriculture (FAO) et grâce à un financement international, un programme d'éradication sera mené à bien $(37,54)$.

Les mâles stériles ont été fournis par l'usine de Tuxtla Gutiérrez au Mexique sous forme de pupes irradiées transportées par avions gros porteurs jusqu'à Tripoli à raison de 3,5 millions à 7 millions par semaine en 1990 et jusqu'à 40 millions par semaine en 1991. Après éclosion des pupes, les mâles stériles ont été dispersés par des petits avions deux fois par semaine dans les zones infestées.

Cette campagne a été un grand succès avec l'éradication du fléau en octobre 91 grâce à cette méthode génétique associée à un strict contrôle des déplacements d'animaux et à une surveillance vétérinaire intense. Elle a coûté 75 millions de dollars américains.

\section{Lutte mécanique}

Le développement d'un système de contrôle des mouches adultes (screwworm adult suppression system : SWASS) reposant sur l'emploi de leurres appâtés a été envisagé et appliqué sur 63000 ha au Texas, mais il a été abandonné en 1935 pour des raisons de coût et d'efficacité réduite.

Pour le moment, deux pièges sont utilisés, uniquement en vue de détecter les mouches adultes.

Le piège mitral est un cylindre de tulle de $60 \mathrm{~cm}$ de haut et $40 \mathrm{~cm}$ de diamètre muni à l'intérieur d'un système non retour et sous lequel est suspendu un plateau portant l'appât. Celui-ci est constitué de morceaux de foie de bovin placés dans de l'eau pendant. 
quelques jours pour obtenir une odeur de tissu lésé en voie de décomposition, qui attire surtout les femelles gravides et dans une moindre mesure les mâles.

Le piège mobile est constitué d'un seau en plastique muni de deux ailettes et contenant un cône intérieur en toile métallique (système non retour). Le piège est appâté. Actuellement, un attractif synthétique (swormlure-4) obtenu par mélange de dix produits chimiques (alcool butylique, bisulfure de diméthyle, acide acétique, acide butyrique, etc.) est efficace et plus sélectif vis-à-vis de Cochlyomyia (53).

Le swormlure-4 est placé dans des flacons de verre non bouchés dans lesquels trempe une mèche. Ils sont placés à l'avant du piège. L'orientation dans le vent permet la diffusion de la traînée d'odeurs.

Ces pièges servent essentiellement aux enquêtes sur la distribution de l'insecte et donc de la maladie, ainsi qu'à évaluer l'efficacité des lâchers de mâles stériles. L'amélioration de leur attractivité par les couleurs est à l'essai (188).

\section{CHRYSOMYA BEZZIANA}

La myiase due à Chrysomya bezziana n'a pas l'impact économique de celle due à C. hominivorax et n'a donc pas donné lieu à des programmes importants de lutte. L'impact bénéfique des oiseaux tels que le pique-bœuf (Buphagus) qui se nourrissent d'ectoparasites du bétail en Afrique a été suggéré, mais on sait aussi qu'ils peuvent parfois aggraver les plaies.

Un essai en Nouvelle-Guinée a prouvé que la méthode des insectes stériles est également praticable pour C. bezziana (31).

\section{GENRES LUCILIA ET CALLIPHORA}

\section{Lutte écologique}

Les myiases cutanées, surtout celles dues aux mouches appartenant aux genres Lucilia, Calliphora, Phormia et Protophormia représentent une menace importante pour l'élevage, en particulier pour l'élevage ovin. Certaines mesures visant à écarter les facteurs prédisposants peuvent cependant en diminuer l'apparition $(92,189)$. Ces mesures consistent à :

- empêcher la souillure de l'arrière-train de l'animal par les matières fécales ou l'urine (vermifugation régulière, tonte des parties internes des membres postérieurs ou ablation chịurgicale de la peau dans la région périnéo-vulvaire, amputation de la queue) ;

- empêcher la décomposition bactérienne de la toison (sélection de races ovines résistantes ou ne présentant pas de plis cutanés importants, application de produits asséchants qui réduisent efficacement l'humidité de la toison dans les zones fessières) (68);

- empêcher les plaies (planification des interventions chirurgicales et des agnelages en dehors de la période estivale, inspection régulière des animaux et traitement immédiat en cas de myiase, traumatisme ou infection ectoparasitaire) ;

- sélectionner des animaux à zone fessière large, plate et sans replis (189), avec de gros follicules pileux;

- détruire rapidement les cadavies. 


\section{Lutte biologique}

Aucune méthode n'est encore utilisée de façon courante.

En Australie, la vaccination du mouton contre Pseudomonas aeruginosa, bactérie impliquée dans la décomposition de la toison, a diminué l'incidence de cette affection et par conséquent le nombre des cas de myiase.

La sélection de moutons plus résistants à la décomposition bactérienne de la toison et à l'attaque des mouches myiasigènes serait possible; elle semble associée à des différences dans la réaction inflammatoire des animaux (137).

Des essais préliminaires avec des souches de Bacillus thuringiensis, capables de coloniser la toison ovine, ont démontré que ces souches protègent les moutons contre la myiase durant une période similaire à celle obtenue avec des régulateurs de croissance tels que la cyromazine (106) (voir ci-dessous). Des formulations à base de $B$. thuringiensis et supplémentées en B-exotoxine ont permis de contrôler les infestations chez les moutons déjà atteints de myiase (105).

\section{Lutte génétique}

Des gènes entraînant une stérilité partielle et une cécité parmi les descendants peuvent être introduits dans les populations naturelles de Lucilia cuprina par translocation chromosomique. Cette technique ainsi que la technique des lâchers de mâles stériles, ont été étudiées au laboratoire et dans des essais de terrain depuis 1980 sur des surfaces de 40 à $2000 \mathrm{~km}^{2}$. Toutefois, avant qu'elles puissent être utilisées à grande échelle, l'élevage en masse des formes portant la translocation et la compétitivité de ces dernières face aux formes sauvages devront être améliorés. Selon Gaafar et coll. (56), le coût d'application de ces méthodes de lutte à des surfaces gigantesques, telles que l'Australie par exemple, semble trop élevé.

\section{Lutte mécanique}

Des pièges pour la capture de Lucilia spp. ont été développés $(6,195)$, mais leur intérêt reste à confirmer.

\section{Produits alternatifs}

Une application de cyromazine à $2 \%$, un régulateur de croissance interférant avec la formation de la cuticule lors des mues, protège le mouton contre les myiases pendant une période allant de huit à seize semaines (105). La cyromazine a été proposée en application pour on (action sur les larves L1 se déplaçant à la surface de la peau) (26). En Nouvelle-Zélande, la cyromazine est utilisée en alternance avec un autre régulateur de croissance, le diflubenzuron (84). Une aspersion avec une formulation appropriée d'ivermectine (ivermectin jetting fluid) à $0,003 \%$ abaisse l'incidence de la myiase de $93 \%$ pendant 13 semaines (49). Toutefois, dans certains pays, les résidus, retrouvés dans la laine après un traitement à l'ivermectine ou au diflubenzuron, constituent un problème (105).

\section{WOHLFAHRTIA MAGNIFICA}

\section{Lutte écologique}

La lutte écologique contre Wohlfahrtia magnifica comprend toutes les mesures hygiéniques rendant les animaux moins attractifs (voir ci-dessus la lutte écologique contre Cochlyomyia), et en particulier celles supprimant les causes de maintien d'un 
microclimat humide dans certaines régions anatomiques (périnée, intercuisse, vulve, etc.) par traitements antiparasitaires internes, par chirurgie (caudectomie, suppression des plis périnéaux), par sélection zootechnique, etc.

L'huile de pin appliquée aux zones anatomiques exposées aux dépôts de larves semble avoir un effet répulsif vis-à-vis des femelles.

\section{Lutte biologique et génétique}

Aucune méthode biologique ou génétique n'est applicable, en particulier les lâchers de mâles stériles, car W. magnifica s'accouple plusieurs fois dans sa vie. L'emploi de la cyromazine à $6 \%$ en traitement pour on assure une protection de 21 jours au maximum en France (4) en agissant comme inhibiteur de croissance des larves.

\section{BOOPONUS INTONSUS ET AUCHMEROMYIA SPP.}

La présence de boue sur les pattes des buffles d'eau semble entraver le dépôt d'œufs par Booponus intonsus ; les éleveurs dans certaines régions asiatiques protègent donc leurs buffles durant la saison sèche en construisant des petits ruisseaux qui parcourent les pâturages.

Puisque les larves hématophages des Auchmeromyia spp. ne survivent pas sur un sol dur ou humide, il est recommandable de cimenter les sols des porcheries.

\section{OESTRIDAE}

\section{Lutte écologique}

Afin de diminuer l'incidence des myiases dues aux Gedoelstia spp. chez les animaux domestiques, il convient de séparer ceux-ci des antilopes, hôtes habituels des Gedoelstia spp.

L'application d'huile de pin autour des nảseaux des ovins empêcherait l'oviposition par Oestrus ovis.

\section{Lutte génétique}

De 1983 à 1986, un essai pilote a été réalisé dans une zone de $3800 \mathrm{~km}^{2}$ de la région frontalière entre le Canada et les Etats-Unis d'Amérique, qui avait préalablement fait l'objet d'un traitement insecticide, afin d'examiner l'efficacité de la méthode des mâles stériles sur les populations d'Hypoderma bovis et d'Hypoderma lineatum. La méthode fut efficace, mais ne sera probablement pas utilisée à grande échelle avant la mise au point d'un élevage simple et bon marché des insectes $(95,96)$.

\section{DIPTÈRES NON-PARASITAIRES}

\section{Lutte écologique}

\section{A l'intérieur des étables}

Du fait de leur importante pullulation, certaines mouches, appartenant notamment aux genres Musca et Fannia, peuvent constituer un véritable fléau dans les étables. Les larves de ces mouches utilisent de préférence des accumulations de matières fécales et de restes d'aliments. Pour que le biotope soit propice au développement larvaire, il doit répondre à certaines conditions écologiques. 
En conséquence, le contrôle écologique de ces mouches dans les étables peut être obtenu par :

a) un nettoyage régulier de l'étable ainsi que la suppression de tout espace où les matières fécales pourraient s'accumuler et ne pas être retirées (par exemple sous les abreuvoirs et mangeoires et sous les cloisons des loges);

b) une modification du milieu afin d'empêcher le développement larvaire, grâce aux interventions suivantes :

- la liquéfaction du fumier obtenue en évacuant les matières fécales dans des fosses à fumier remplies d'eau. Un défaut de construction de ces fosses fréquemment observé est leur profondeur insuffisante. Dans ce cas, une croûte se forme à la surface du purin qui permet la reprise du développement larvaire de la mouche domestique. Une agitation mécanique du purin peut remédier à cette situation ;

- le séchage du fumier : cette solution est utilisée dans certains poulaillers où le fumier s'accumule sous les cages pendant une période relativement longue. L'utilisation de ventilateurs peut accélérer le séchage du fumier dans la fosse. Tout écoulement d'eau dans cette fosse (par exemple des fuites dans la distribution d'eau de boisson) doit être évité.

En été, le remplacement de la paille dans les loges des veaux par de la sciure de bois entraîne une réduction du nombre de mouches dans l'étable.

Dans les étables où les larves de Hermetia illuscens (Diptera : Stratiomyidae) se développent dans le fumier, le milieu devient impropre au développement larvaire des autres mouches.

\section{En dehors des étables}

Une importante pullulation de mouches sur les tas de fumier ou les silos d'ensilage peut être entravée en recouvrant ceux-ci avec une toile de plastique. L'augmentation de la température qui en résulte détruit les larves. L'entassement et le compactage du fumier, ou méthode biothermique, ne sont efficaces qu'en profondeur mais pas en surface.

Enfouir le fumier ou injecter le purin dans le sol empêchent également la prolifération des mouches. Il en est de même par épandage en couche mince sur les champs par temps sec.

Les coléoptères coprophages participent activement à la dégradation de la bouse de vaches et contribuent ainsi au contrôle des mouches qui utilisent la bouse comme gîte larvaire. Dans certaines régions, des bousiers exotiques ont été importés pour contrôler les populations de Musca vetustissima et de Haematobia exigua (Australie) ou de Musca autumnalis et de Haematobia irritans (Etats-Unis d'Amérique). Bien que la majorité de ces introductions ait abouti à une dégradation nettement accélérée des bouses (99), les opinions des chercheurs sur la capacité de ces coléoptères à contrôler les mouches sont partagées. Le contrôle réalisé est parfois local ou temporaire parce qu'insuffisant en saison chaude. On peut se demander également si ces coléoptères n'auraient pas une influence négative sur certains prédateurs naturels des mouches.

\section{Lutte biologique}

Pour les stades immatures des mouches vivant en étroite association avec le bétail, le taux de mortalité naturelle, très important, est en majeure partie attribuable aux prédateurs, parasitö̉des, parasites ainsi qu’à certains pathogènes. 


\section{Comment favoriser le contrôle biologique?}

Trois possibilités sont envisageables :

- l'importation d'ennemis des mouches dans les régions où ils sont absents ou rares,

- la multiplication de certains prédateurs, parasites ou pathogènes dans des élevages ou laboratoires dans le but de les utiliser ultérieurement sur le terrain,

- la protection des ennemis déjà présents sur place.

Cette troisième solution implique certaines mesures et précautions sur le plan de la lutte chimique et du traitement du fumier :

a) Une lutte intégrée combinant la lutte biologique et la lutte chimique pour contrôler les mouches suppose :

- l'utilisation contre les mouches adultes de formulations insecticides qui n'atteignent que les espèces nuisibles et préservent les arthropodes bénéfiques à la lutte biologique (par exemple, appâts insecticides, formulations pour on sur le bétail, etc.),

- l'usage de produits assez sélectifs, comme la cyromazine ou le diflubenzuron, lors d'un traitement insecticide du fumier afin de ne pas supprimer les arthropodes utiles $(19,204)$.

b) La présence dans le fumier d'ivermectine perturbe le développement de certains prédateurs des mouches; son utilisation dans des formulations à libération lente est à éviter dans les régions où les mouches associées au bétail sont abondantes.

c) L'état de sécheresse d'un fumier est défavorable à la multiplication des mouches mais propice aux prédateurs et parasitoïdes.

d) Dans certains élevages avicoles, on laisse le fumier s'accumuler sous les cages des poules pondeuses pendant toute la durée de la ponte. Après celle-ci, on procède à un nettoyage à fond de toute l'étable. Cette élimination complète du fumier supprime simultanément la population des parasitoïdes et des prédateurs. Dans ce cas, il est recommandé d'ensemencer les matières fécales fraîches avec de vieux excréments qui hébergent encore des prédateurs et/ou des parasites.

\section{Les différents organismes contribuant à la lutte biologique}

\section{Parasitö̈des}

Les parasitoïdes, qui pondent leurs œufs dans les pupes ou larves des mouches nuisibles, sont des atouts intéressants dans la lutte biologique. Les parasitoïdes les plus efficaces sont des hyménoptères appartenant aux familles des Pteromalidae et des Encyrtidae (Tachinaephagus spp.). Du fait que, dans le fumier, un pourcentage parfois important de pupes est trouvé porteur de ces parasitoïdes, ceux-ci ont été élevés et lâchés en masse dans des étables comme méthode de contrôle. Certaines espèces de Pteromalidae (Muscidifurax spp., Spalangia spp., Sphegigaster sp., Nasonia vitripennis, Pachycrepoideus vindemiae et Urolepis rufipes) sont même commercialisées à cet effet. Cependant, le lâcher de parasitoïdes n'est pas toujours couronné de succès. Le résultat dépend de plusieurs facteurs : l'adaptation de l'espèce aux conditions climatiques locales, le rapport entre le nombre des parasitoïdes et des hôtes, la compétition entre différentes espèces de parasitoïdes, la programmation et la fréquence des lâchers, la nature et les propriétés physiques du fumier, la localisation et l'espèce de la pupe à parasiter, les insecticides utilisếs dans l'étable et leur mode d'application, etc. (168). 


\section{Prédateurs}

Des acariens mésostigmates appartenant aux familles des Macrochelidae, Uropodidae et Parasitidae se retrouvent fréquemment sur les excréments des animaux domestiques où ils se nourrissent en particulier des œufs et des premiers stades larvaires des mouches.

Certains coléoptères (spécialement parmi les familles des Staphylinidae et Histeridae) sont également capables de consommer plusieurs dizaines d'œufs ou de larves par jour. Parmi ces coléoptères figure Alphitobius diaperinus, jadis réputé pour les dégâts qu'il infligeait aux matériaux d'isolation dans les étables. Actuellement, les matériaux d'isolation étant plus résistants contre ce genre d'attaques, on peut se demander si la présence d'un nombre modéré d'A. diaperinus dans l'étable ne serait pas bénéfique.

Le dernier stade larvaire d'Ophyra aenescens, un diptère originaire du Nouveau Monde qui envahit actuellement l'Europe, est un prédateur facultatif des larves d'autres diptères (entre autres, Musca et Fannia sp.). Cette mouche se rencontre principalement dans les porcheries et les exploitations d'engraissement pour veaux, probablement parce qu'elle préfère un biotope larvaire assez humide. Les adultes sont peu actifs et ne sont donc pas nuisibles. Actuellement $O$. aenescens est utilisée (20) et commercialisée dans plusieurs pays pour un contrôle biologique de la mouche domestique. Il en est de même avec les prédateurs suivants : I'acarien Macrocheles spp. et le coléoptère Carcinops pumilio.

Des expériences ont démontré que certains oiseaux (par exemple le rossignol japonais : Leiothrix lutea et le canard musqué : Cairina moschata) sont capables de consommer un nombre important de mouches adultes et pourraient contribuer à leur contrôle dans les étables (61).

\section{Parasites et pathogènes}

Plusieurs nématodes appartenant aux genres Steinernema, Heterorhabditis et Heterotylenchus infectent et tuent ou stérilisent des diptères. Neoaplectana carpocapsae, dont la production en masse est possible, est commercialisé. Malheureusement, sur le terrain, la survie de ces nématodes et leur aptitude à trouver l'hôte sont trop faibles pour qu'ils soient des candidats valables pour la lutte contre les mouches associées au bétail.

Dans certains pays, des souches de $B$. thuringiensis produisant des exotoxines toxiques pour les diptères, sont en vente pour lutter contre les mouches des étables. Les résultats de ces applications sont cependant variables et des études supplémentaires sur les facteurs qui influencent la survie de ces souches dans le purin et la production des toxines semblent être nécessaires (87).

La mycose par Entomophtora muscae est un moyen de contrôler localement une population de mouches domestiques. Toutefois, avant d'utiliser ce pathogène sur le terrain, il convient d'étudier davantage la conservation des conidies et la spécificité des différentes souches vis-à-vis de certains hôtes.

\section{Lutte génétique}

La stérilisation de $M$. autumnalis par irradiation ayant été optimisée récemment (109), la technique des insectes stériles pourrait de nouveau être envisagée pour lutter contre cette mouche. 


\section{Lutte mécanique}

Les attrape-mouches géants, imprégnés de glu, et les pièges olfactifs ne sont généralement pas suffisants pour supprimer une population de mouches dans une étable, mais ils peuvent compléter avantageusement la lutte chimique en retardant le développement d'une résistance.

\section{Produits alternatifs}

Certains produits empêchent l'insecte d'atteindre le stade adulte en régulant la nature de la nouvelle cuticule au moment des mues (les juvénoïdes tels que le méthoprène et le pyriproxyfène) ou en perturbant la formation de cette cuticule (diflubenzuron, cyromazine). De nos jours, ces produits sont fréquemment utilisés, soit en aspersion sur les gîtes, soit après incorporation aux aliments ou pierres à lécher des animaux domestiques. Ces procédés compromettent sérieusement la survie des stades pré-imaginaux des Musca et Ophyra spp. dans le milieu larvaire ainsi traité (19).

\section{DIPTÈRES PIQUEURS}

\section{GLOSSINES}

La lutte contre les mouches tsé-tsé s'est déroulée à vaste échelle essentiellement dans le domaine vétérinaire. L'objectif était de supprimer l'insecte dans les zones pastorales de savanes relativement sèches. Les insecticides organochlorés ont été le support de la lutte contre les glossines savanicoles.

La descente progressive de l'élevage en zone humide offre une nouvelle situation face à laquelle ce sont les méthodes non insecticides qui sont recherchées : espèces de glossines ripicoles vivant près des cours d'eau, forte pluviométrie (lavage des insecticides), saison sèche courte (faible latitude d'intervention par pulvérisation) et isolement impossible des zones traitées. De plus, le manque croissant de moyens humains et financiers et le souci de protéger l'environnement favorisent la réhabilitation des luttes non chimiques.

\section{Lutte écologique}

L'objectif de la lutte écologique est, soit de rendre inhospitalier les biotopes à glossines en supprimant le couvert végétal, soit de supprimer leurs hôtes nourriciers, qui sont souvent aussi des réservoirs de trypanosomes. Avant la découverte des insecticides, la pratique des éclaircissements totaux pour protéger un ranch, un village, une piste à bétail (« corridors »), un gué, etc., était courante. Sur.de grandes surfaces de savanes arborées, le déboisement était réalisé à l'aide de gros tracteurs reliés entre eux par une lourde chaîne. Dans quelques cas récents, des produits phytocides ont été appliqués par badigeonnage après scarification des troncs.

S'ils ne sont plus utilisés pour la lutte contre les glossines, les déboisements s'intensifient en Afrique sous l'effet des pressions agricoles.

En 1895, une panzootie de peste bovine a fait disparaître la grande faune sauvage, ce qui entraîna une chute brutale de la densité de glossines en Afrique orientale et australe. Après cette observation et en l'absence d'autres moyens de lutte, l'élimination systématique ou sélective des principaux hôtes nourriciers des glossines a été pratiquée en Rlodésie (actuel Zimbabwe), en Ouganda, au Botswana et en Afrique du Sud 
$(52,90)$. Cette méthode onéreuse et moyennement efficace est inacceptable aujourd'hui, car des moyens plus performants et plus écologiques sont disponibles.

Elle est cependant encore appliquée, ponctuellement, au niveau des « corridors » ou «zones-tampon»séparant les zones assainies des zones infestées au Zimbabwe, afin d'éviter que la faune ne favorise le passage des glossines.

Il convient de noter que l'assèchement de rivières en aval d'un barrage ou l'inondation en amont provoquent de profondes transformations de la végétation, de l'état des sols et de l'occupation humaine et animale, qui ont une action certaine sur les pupes dans le sol et sur la distribution de la population adulte, mais de tels travaux ne sont pas entrepris dans cet objectif et leur effet est généralement passager.

\section{Lutte biologique}

Les glossines subissent, à l'état pupal, la prédation de fourmis, de coléoptères divers, de certains oiseaux terrestres et de quelques mammifères insectivores ; à l'état adulte, d'araignées, de libellules, de quelques hyménoptères et de diptères (Azilidés). Cette prédation semble toutefois difficilement utilisable comme moyen de lutte (90).

Les seules campagnes de lutte biologique utilisant un parasite ont été faites dès 1925 au Nyasaland, au Nigeria et en Tanzanie, par lâcher sous forme de pupes parasitées d'un Hyménoptère (Nesolynx sp.), mais sans grand succès.

Le parasitisme des pupes à certaines saisons par d'autres hyménoptères (Chrestomutilla sp.) et diptères (Exhyalanthrax sp.) peut atteindre plus de $50 \%$ (98).

Malheureusement, l'utilisation de ce parasitisme naturel dans la lutte contre les glossines dépend de problèmes non résolus, liés à la biologie et à l'écologie de ces différents parasites, aux possibilités de les élever en masse et à leur manque de spécificité.

L'utilisation de micro-organismes pathogènes dans la lutte contre les glossines n'est guère plus avancée.

Sous des conditions précises au laboratoire, les glossines adultes peuvent être très sensibles à certains champignons, et l'absorption de sang infecté par certaines bactéries a un effet létal ; mais les possibilités de contamination dans la nature sont très réduites.

Un virus qui ressemble à un Baculoviridé provoque une forte inflammation des glandes salivaires, associée à une dégénérescence des ovarioles chez la femelle et à une stérilité chez le mâle, sans entraîner de mortalité importante dans la nature. Les mâles infectés, tout en étant stériles, ont un comportement sexuel normal. Les spermathèques des femelles restent vides de spermatozoïdes, mais ces femelles deviennent réfractaires à un deuxième accouplement, ce qui laisse entrevoir une possibilité d'utiliser des lâchers de mâles stérilisés par ce virus (91), d'autant plus que la possibilité de transmission de la mère à sa fille est intéressante.

L'utilisation d'un mimétique de l'hormone juvénile (pyriproxyfène) comporte des aspects de lutte chimique, de lutte biologique et de lutte génétique.

Des essais ont montré que ce produit empêche la production d'une descendance viable des femelles pendant toute leur vie par perturbation de la métamorphose larvaire (100). Il est d'une bonne stabilité en conditions tropicales. Mélangé à une huile, il imprègne par contact les femelles piégées qui demeurent stériles, et permet aux mâles de se charger également du produit pour le transmettre aux femelles dans la nature au moment de la copulation. Au Zimbabwe, la plupart des pupes de Glossina morsitans morsitans et de Glossina pallidipes collectées dans une zone expérimentale ont eu un 
développement incomplet (70). Il en est de même pour Glossina palpalis palpalis en Côte d'Ivoire (Laveissière, communication personnelle).

Certains produits sont capables d'empêcher la synthèse de la chitine. Le diflubenzuron, en application topique au laboratoire, entraîne la production de descendants anormaux pendant toute la vie de la femelle tout en étant biodégradable et non toxique pour la faune autre que celle des arthropodes. L'application sur le terrain, en pulvérisation ou en imprégnation sur des leurres (pièges, écrans), dépend actuellement de problèmes de formulation.

\section{Lutte génétique}

On désigne sous le terme de «lutte génétique ", l'emploi de toutes les conditions ou méthodes de traitement susceptibles de diminuer le potentiel reproducteur des insectes nuisibles, par altération ou modification du matériel héréditaire.

Bien que généralement incluse dans la lutte biologique, la lutte génétique s'en distingue en ce qu'elle ne fait pas appel, pour détruire une espèce nuisible, à d'autres espèces vivantes ni à des modifications de l'environnement. La lutte génétique n'utilise en effet que des individus appartenant à l'espèce visée pour provoquer sa propre destruction. C'est pourquoi on a pu la qualifier de lutte autocide ou de méthode d'autodestruction.

C'est une technique très spécifique, non polluante et ne présentant aucun danger pour les autres espèces animales. Elle a de plus l'avantage sur la plupart des autres méthodes, d'être d'autant plus efficace que la densité de la population visée est faible ; en outre, les individus porteurs d'altérations génétiques, à condition d'être compétitifs, sont plus aptes que l'homme à déceler les petites populations sauvages résiduelles dans le milieu naturel.

Cette méthode de lutte paraît devoir s'appliquer particulièrement bien à la lutte contre les glossines, dont les populations sont généralement peu denses (du moins celles du groupe palpalis) et ont un très faible taux de reproduction.

Le principe fondamental de la lutte génétique consiste à utiliser des facteurs aboutissant à un échec de la reproduction.

On peut employer divers moyens, dont les principaux consistent à :

- introduire dans la population des individus mâles préalablement stérilisés au laboratoire par l'action d'agents physiques (radiostérilisation) ou chimiques (chimiostérilisation), qui entreront en compétition, pour l'accouplement, avec les mâles normaux de l'espèce correspondante ;

- stériliser directement, dans la nature, le plus grand nombre possible d'individus des deux sexes au moyen d'agents chimiques utilisés selon les mêmes modalités que les insecticides, ou au moyen de pièges permettant de relâcher les individus capturés après leur contact avec un chimiostérilisant ;

- favoriser, au sein de la population à détruire, les accouplements d'insectes appartenant à des espèces ou sous-espèces voisines, qui ne donneront pas de descendants ou seulement des descendants stériles (hybridation) ou qui entraîneront la mort de la femelle;

- sélectionner des individus, viables et fertiles, porteurs d'anomalies héréditaires, soit naturelles, soit induites (manipulations génétiques). Ces individus, en s'accouplant avec des individus normaux, introduisent dans la population sauvage des facteurs génétiques entraînant à terme son déclin. 
Quelques manipulations génétiques au laboratoire par irradiation à faibles doses ont permis de créer trois familles d'homozygotes de translocations, engendrant des hétérozygotes partiellement stériles, mais les individus produits étaient peu ou pas compétitifs. De plus, l'élevage d'individus génétiquement anormaux est difficile (38).

De même, l'observation chez G. m. morsitans de mutants (corps de couleur ocre ou yeux de couleur saumon) porteurs d'un gène létal n'a pas eu d'applications pratiques sur le terrain (faible longévité, grande réceptivité aux trypanosomes, compétitivité non étudiée).

La production d'insectes transgéniques est pour le moment une possibilité éventuelle de lutte, avec toutes les incertitudes inhérentes à cette démarche. L'introduction dans les symbiontes intestinaux de gènes impliqués dans la dégradation de la chitinase et l'utilisation du glucose est actuellement à l'étude en laboratoire (39).

Des essais d'hybridation au laboratoire ont eu lieu entre sous-espèces du groupe morsitans ( $G$. m. morsitans $\times G$. m. centralis ou $G$. $m$. submorsitans), avec des degrés élevés de stérilité dans la descendance. Une tentative historique eut lieu sur le terrain en 1947 en introduisant dans une zone à Glossina swynnertoni des pupes de G. m. centralis récoltées dans une autre zone, mais l'espèce introduite n'a pu se maintenir.

Seule la méthode du mâle stérile a donné lieu à des expériences au laboratoire et sur le terrain qui ont débouché sur des projets opérationnels.

Cette méthode s'applique bien aux glossines du fait de leurs caractéristiques biologiques :

- faible taux de reproduction des femelles (une seule larve tous les neuf à dix jours);

- densité relativement faible des populations ;

- accouplement généralement unique des femelles avec effet déterminant pour le reste de leur vie ;

- stock non renouvelable de spermatozoïdes chez le mâle.

Le principe consiste à lâcher sur un mode inondatif des mâles stériles qui vont entrer en compétition avec les mâles sauvages pour inséminer les femelles vierges avec un sperme lésé. Les femelles resteront alors infécondes pour le reste de leur vie.

La stérilisation des mâles peut s'obtenir par voie physique (en général par rayons gamma) ou par voie chimique après contact avec des agents alkylants : tepa, metepa, tétramine, etc. $(38,40,100)$.

La voie chimique a été expérimentée de 1967 à 1968 lors de lâchers d'adultes et de pupes stérilisés sur des îles du lac Kariba (ex-Rhodésie du sud) en association avec des pulvérisations insecticides (41), mais n'est plus employée, les produits impliqués étant trop dangereux pour les manipulateurs. Ils sont désormais remplacés par des régulateurs de croissance (pyriproxyfène, par exemple), avec lesquels les glossines mâles et femelles entrent en contact lorsqu'elles pénètrent dans un piège de capture qui devient un piège stérilisant (100).

Pour les lâchers inondatifs, l'obtention des mâles stériles se fait essentiellement par l'élevage en masse des glossines, les surplus de mâles étant soumis, soit à l'état pupal, soit à l'état adulte, à un rayonnement gamma de 70 à $150 \mathrm{~Gy}$ selon les espèces (dose délivrée en quelques minutes) avant d'être libérés dans les zones infestées.

Après une phase d'expérimentation au laboratoire (85) puis sur le terrain, les paramètres operationnels ont été définis pour trois glossines d'Afrique occidentale (34). 
De plus, les progrès dans les techniques d'élevage en masse, en particulier l'alimentation in vitro (plaques d'alimentation à partir du sang d'un abattoir) (86) ont permis d'obtenir des effectifs importants jamais atteints auparavant (330 000 femelles au Burkina Faso) pour cet insecte à très faible taux de reproduction.

Trois projets importants ont été réalisés sur le terrain. En Tanzanie, en 1982, sur un ranch d'élevage de $195 \mathrm{~km}^{2}$, des lâchers de pupes irradiées (G. m. morsitans) ont eu lieu pendant 15 mois (deux fois par semaine) après deux traitements aériens insecticides non rémanents (endosulfan) pour faire baisser préalablement les densités naturelles. La chute finale de densité n'a été que de $81 \%$ en moyenne, en raison des ré-infestations (barrières non étanches) (203).

Le plus grand projet a été réalisé de 1980 à 1985 au Burkina Faso contre trois espèces de glossines simultanément (Glossina tachinoides, G. p. gambiensis et G. m. submorsitans) dans une zone agropastorale de $3000 \mathrm{~km}^{2}$. En saison sèche, les densités naturelles ont été abaissées par la mise en place de plus de 7000 écrans imprégnés d'insecticides le long du système hydrographique avec un effet de rajeunissement de la population femelle. Dès le début des pluies, les mâles stériles ont été lâchés. En deux ans, un million de mâles stériles ont été libérés (à l'état adulte) et l'élimination effective des trois vecteurs a été obtenue $(35,149)$. Il a été démontré qu'il fallait effectuer des lâchers tous les deux kilomètres linéaires, en fin de saison sèche, avec un ratio de dix mâles stériles pour un mâle sauvage et à un intervalle de une à deux semaines (34).

Un projet similaire reprenant la même stratégie a été réalisé au Nigeria, associant une phase initiale de piégeage et une phase de lâchers de mâles stériles pour aboutir à l'élimination de G. p. palpalis sur $1500 \mathrm{~km}^{2}$ (184).

Cette stratégie de lutte intégrée, définie au Burkina Faso, met en œuvre, d'une part une technique de piégeage (écrans insecticides) applicable en saison sèche (absence de pluies, concentration des glossines, accessibilité, etc.) qui fait chuter considérablement la densité de glossines, et d'autre part les lâchers de mâles stériles plus opérationnels en saison des pluies et capables d'éliminer la population résiduelle, la plus difficile à supprimer.

Actuellement, avec l'appui de la division mixte FAO-AIEA (Agence internationale pour l'énergie atomique, Vienne), un projet d'élimination de Glossina austeni est mis en cuvre à Zanzibar en associant plusieurs techniques (applications insecticides sur le bétail, piégeage) à la méthode du mâle stérile.

La méthode du mâle stérile est propre, sélectivement dirigée contre l'espèce nuisible et peut s'appliquer en toutes saisons. Son utilisation n'est envisageable qu'avec un objectif d'éradication. Sa mise en œuvre est plus onéreuse à court terme (création d'élevages d'insectes) que les autres techniques et son efficacité n'est pas immédiate (plusieurs mois). Elle nécessite un isolement parfait des zones à traiter pour limiter la durée d'application. Elle permet de prendre le relais d'autres techniques de lutte comme méthode de «finition », en particulier pour les glossines de galeries forestières.

L'emploi de pièges «stérilisants » sera peut-être le moyen de s'affranchir de l'élevage de milliers d'insectes.

\section{Lutte mécanique}

Pour les glossines, le moyen mécanique de lutte est essentiellement représenté par des leurres qui attirent de façon visuelle ou/et olfactive l'insecte, soit pour le capturer (et éventuellement le stériliser), soit pour le détruire. 
L'emploi de répulsifs efficaces empêchant le bétail d'être piqué n'existe pas, bien que les éleveurs utilisent certains extraits végétaux, appliqués sur le pelage du bétail ou administrés par voie orale, lorsque les troupeaux traversent des zones à forte infestation.

Les déplacements des zébus vers les zones humides du fait des sécheresses, les moyens humains et matériels limités des services de lutte, l'instabilité politique, la compétition pour l'occupation des sols entre éleveurs et agriculteurs, la raréfaction des financements à long terme, le souci de protection de l'environnement sont autant de facteurs qui orientent actuellement la stratégie de lutte plutôt vers un contrôle des populations de glossines que vers leur élimination.

Dans ce nouveau contexte, les techniques de piégeage ont retrouvé une grande actualité. Si divers pièges et écrans sont inventés entre 1910 et 1960 , les espoirs dans ces techniques ne se sont vraiment consolidés que depuis 1970, à la suite de nombreux travaux de recherche en Afrique occidentale et australe $(30,191)$. Ces travaux ont simplifié les systèmes et les ont rendu beaucoup plus efficaces (réduction de $95 \%$ à $98 \%$ des densités de glossines) grâce à l'avènement des pyréthrinoïdes (à effet de contact foudroyant) et à la découverte de couleurs attractives et de quelques produits olfactifs efficaces pour certaines espèces de glossines (69).

Les systèmes attractifs sont constitués essentiellement par les pièges et les écrans. Plus récemment, l'imprégnation insecticide des animaux fait de ceux-ci des " pièges vivants".

Les leurres doivent activer la glossine au repos, l'attirer et entraîner sa pose sur un support imprégné d'un insecticide ou d'un produit « stérilisant », ou bien permettre sa capture par pénétration dans un système non-retour.

Les pièges ont en commun un corps ou enceinte, de forme variable (prisme, cylindre, cône, cube), une surface attractive qui est l'enceinte elle-même associée ou non à des écrans, un dispositif anti-retour (pyramide ou fente entre deux plans en $V$ renversé) et une cage de capture selon les besoins. Ils sont imprégnés ou non d'insecticides.

Le piégeage est en plein développement grâce à une meilleure connaissance du fonctionnement des leurres qui dépend, d'une part de facteurs propres à la glossine (durée de vol, faim, sexe, âge, gestation, espèce, etc.) conditionnant sa disponibilité, sa vision et son olfaction, et d'autre part de facteurs propres aux leurres (tailles, formes, couleurs, contraste, emplacement, qualité des tissus, produits attractifs, etc.) $(33,55,191)$.

L'attraction visuelle est corrélée positivement avec la réflectivité dans la gamme du bleu et négativement avec celle de l'ultra-violet. Par contre la pose est corrélée positivement avec une haute réflectivité dans l'ultra-violet.

Ces observations ont abouti à l'emploi en association de la couleur bleu royal (attraction) et de la couleur noire (pose), tant pour les pièges que pour les écrans, afin d'obtenir à la fois attractivité et efficacité, aussi bien pour la lutte que pour la réalisation de barrières.

Les principaux modèles de pièges et d'écrans en usage actuellement et reconnus comme les plus pratiques et efficaces sont décrits ci-après (Fig. 1).

\section{Pièges et écrans en usage en Afrique occidentale et centrale}

\section{Le piège biconique de Challier-Laveissière (Burkina Faso)}

Il comprend deux cônes reliés à leur base ( $80 \mathrm{~cm}$ de diamètre), l'un en tulle, l'autre en tissu bleu phtalogène percé de quatre ouvertures. A l'intérieur, deux écrans noirs se coupent verticalement en leur milieu. Il comporte un piquet vertical fiché au sol et, soit 
un cône de soutien portant une cage de collecte (piège de capture), soit un tampon de coton intercalé entre le cône en tulle et le piquet (piège de lutte). C'est un piège efficace surtout contre les glossines ripicoles ( $G$. palpalis, $G$. tachinoides) mais relativement cher, donc servant surtout aux enquêtes. Il est à l'origine de toute une génération de pièges.

\section{Le piège pyramidal de Lancien-Gouteux (Congo)}

Il est constitué d'une pyramide supérieure en tulle moustiquaire coiffant deux écrans (bleu et noir) se coupant verticalement à angle droit et maintenus par deux baguettes de bois. Le système de collecte est variable (nasse, sachet, cage). Ce piège est surtout efficace vis-à-vis de Glossina fuscipes, $G$. palpalis et $G$. tachinoides.

\section{Le piège bipyramidal de Gouteux et coll. (République Centrafricaine)}

La pyramide inférieure est en plastique bleu, complétée par trois panneaux latéraux bleus. Elle entoure trois écrans en plastique noir. Elle est surmontée par une pyramide en tulle et un système de capture (bouteilles de plastique). Ce piège peu onéreux est efficace au moins pour $G$. f. fuscipes.

\section{Le piège monoconique "Vavoua » de Laveissière et coll. (Côte d'Ivoire)}

Un cône de tulle moustiquaire coiffe trois écrans se coupant verticalement ; la partie centrale de chaque écran est noire et la partie externe bleue ; les écrans sont sous-tendus au niveau de la partie inférieure par des baguettes de bois. Ce piège s'adresse surtout aux glossines ripicoles et préforestières du groupe palpalis et constitue un bon compromis efficacité/coût.

\section{Le piège monoconique de Mérot (Burkina Faso)}

Un cône de tulle moustiquaire coiffe trois écrans se coupant verticalement, dont la partie supérieure est noire et la partie inférieure bleue. Ce piège est efficace à la fois contre G. tachinoides (glossine ripicole) et G. m. submorsitans (glossine savanicole).

\section{L'écran de Challier-Gouteux-Laveissière (Côte d'Ivoire)}

Simple morceau de tissu bleu d'environ $1 \mathrm{~m}^{2}$ imprégné de deltaméthrine, cet écran est suspendu soit à une potence métallique fichée au sol, soit à une latte de bois fixée à une branche d'arbre. Il est destiné à la lutte contre $G$. palpalis et $G$. tachinoides après imprégnation insecticide (pyréthrinoïdes).

\section{L'écran de Laveissière et coll. (Côte d'Ivoire)}

Constitué d'une surface attractive (tissu bleu phtalogène en coton/polyester), il est flanqué de deux bandes interceptrices de voile noir en polyamide dans un rapport de 1 à 2 . Ce tissu assure une rémanence longue de cinq à six mois après l'imprégnation avec la deltaméthrine. Cet écran est utilisé contre $G$. palpalis et $G$. tachinoides lors des campagnes de lutte.

\section{L'écran de Mérot-Filledier (Burkina Faso)}

Il est formé d'un carré attractif de tissu à moitié noir et à moitié bleu $(0,7 \times 0,7 \mathrm{~m})$ flanqué de deux rectangles de tissu moustiquaire $(0,5 \times 0,5 \mathrm{~m})$ que les glossines vont heurter, se chargeant ainsi d'insecticide. L'ensemble est mobile sur un cadre pivotant. Il est efficace contre G. $m$. submorsitans et $G$. tachinoides.

Le choix d'un modèle dépend des espèces visées, des objectifs (enquête, surveillance, lutte) et des surfaces à traiter. 


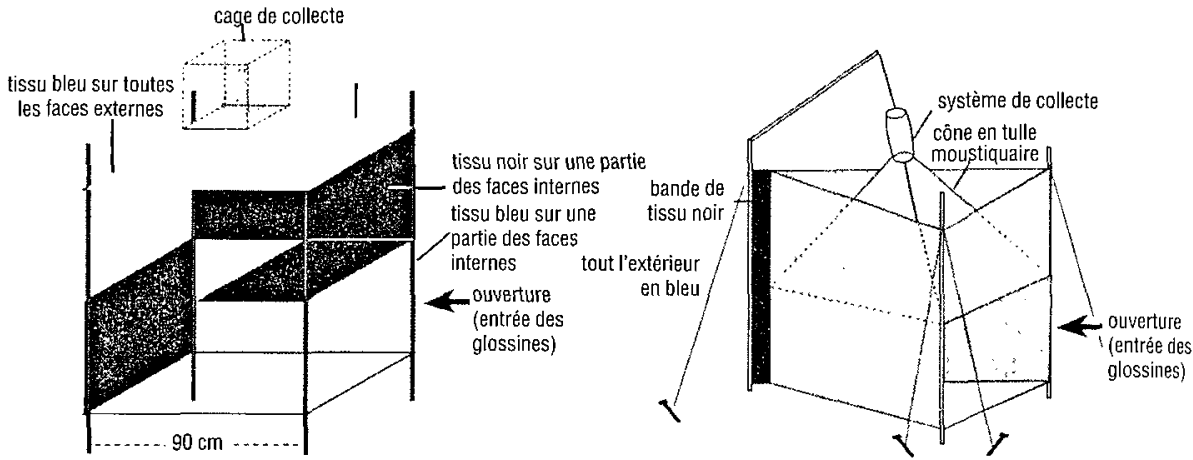

Piège cubique de Flint F3 (Bull. entomol. Res., 1985, 75, 529-534)

(adapté de Flint, Vale, communications personnelles)

Pì̀ge «Epsilon » (adapté de Phelps, communication personnelle, et VALE, FAO Meeting, 1988, Accra, Ghana)

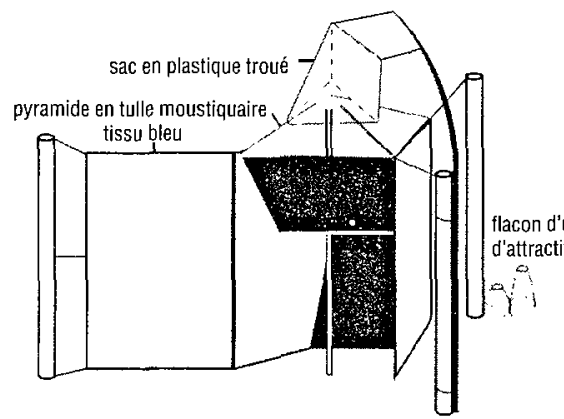

Piège NG-2G de Brightwell et coll. (adapté de BrJGHTwELL et coll., Med. vet. Entomol, 1991, 5, 153-164)

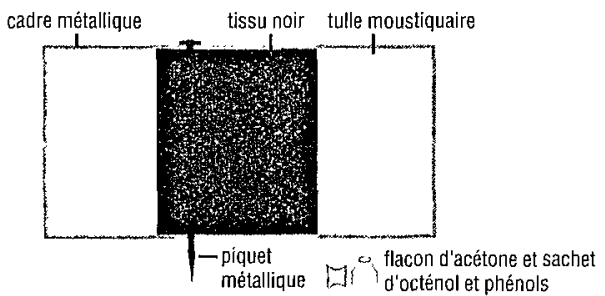

Ecran mobile de Vale (adapté de Vale el coll., Bull, entomol. Res., 1985, 75, 219-231) (plus récemment, cet écran est constitué entièrement de tissu noir)

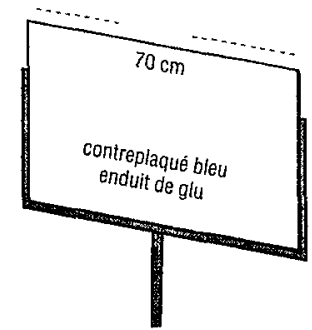

Pìge Chuka (adapté de Madubunyı, Insect Sci. Applic., 1992, $11[3], 309-313)$

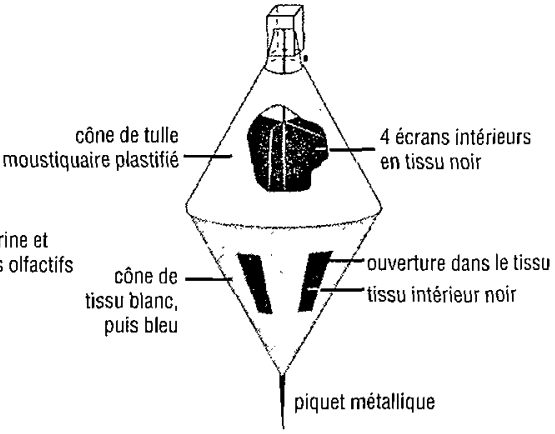

Piège biconique Challier-Laveissière (CHALLIER et coll., Cah ORSTOM, série Entomol. méd. Parasitol., 1973, 11 [4], 251-262)

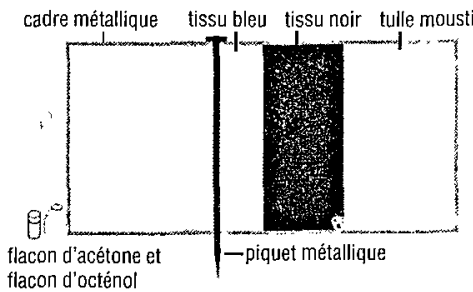

Ecran mobile de Mérot-Filledier (adapté de MÉrot et coll., Rev. Elev. Méd. vét. Pays trop., 1985, 38 [1], 64-71)

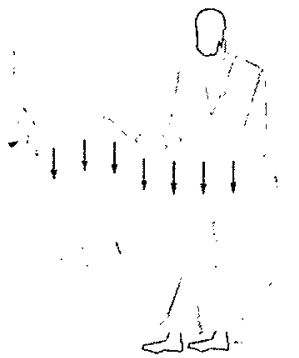

Application d'une formulation pour on sur la ligne dorsale d'un bovin, à l'aide d'un flacon doseur (ou d'un pistolet) (adapté de CUISANCE - Le piégeage des tsé-tsé. Etudes et Synthèses IEMVT, 1989, $N^{\circ} 32$ )

FIG. 1 


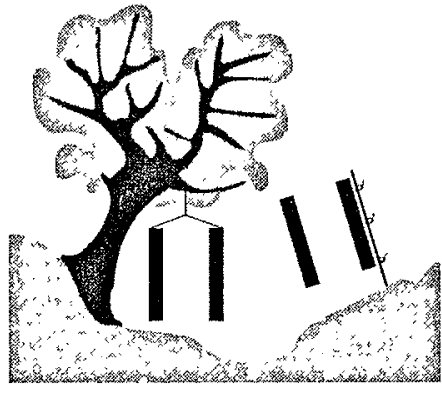

Ecran de Laveissière (1986). Mode d'installation sur le terrain (LAVEISSIERE et coll., Cah. ORSTOM, série Entomol. méd. Parasitol., 1987, 25 [3/4], 145-164)

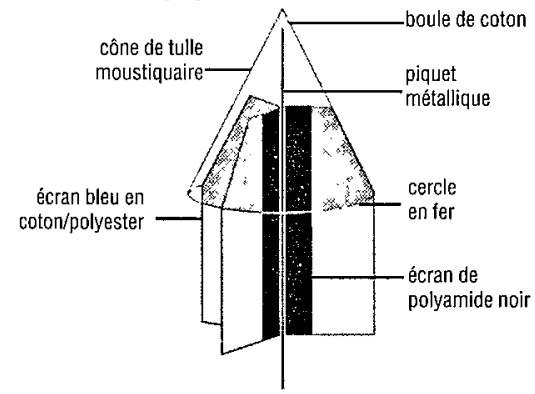

Piège monoconique «Vavoua » de Laveissière (LAVEISSIËRE Les glossines. Guide de formation et d'information. Série Lutte antivectorielle, 1988)

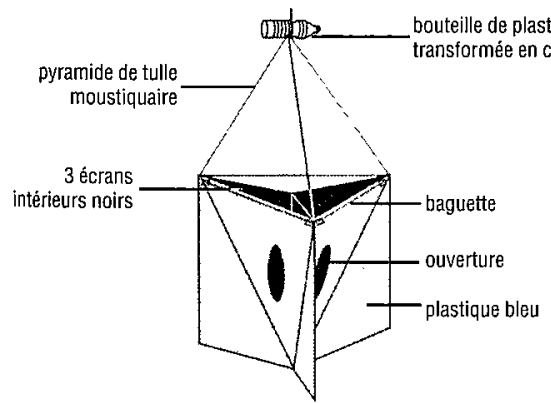

Piège pyramidal de Gouteux et Le Gall (adapté de GouTEux et coll., Rev. mond. Zootechn., 1992, 1, 33-43)

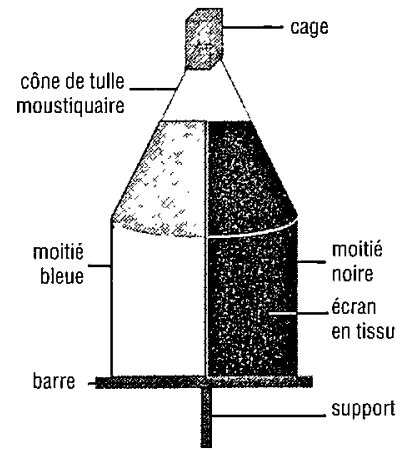

Piège de Okoth (adapté de Окотн, Ann. rrop. Med. Parnsitol., 1991,85 [3], 309-314)

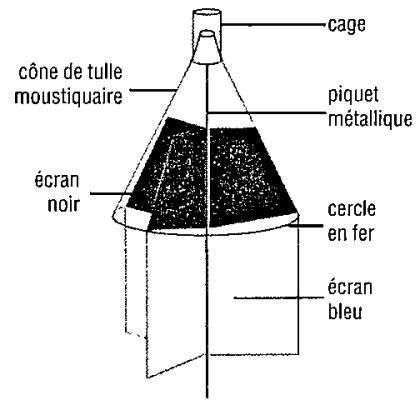

Piège monoconique de Mérot (Mérot, communication personnelle). Centre de recherche sur les trypanosomoses animales, Bobo-Dioulasso, Burkina Faso

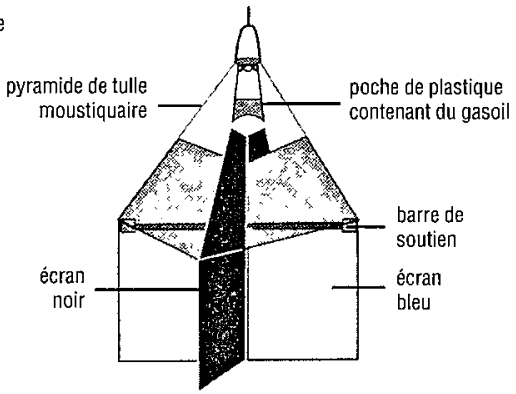

Piège pyramidal de Gouteux/Lancien (adapté de GouTEuX et coll., Ann. Soc. belge Méd. trop., 1987, 67,37-49 et de LANCIEN et GOUTEUX, Afr. méd., 1987, 26 [258], 647-652)

c) ORSTOM - CIRAD - Université Paris IV

Tiré de : Brunhes J., Cuisance D., Geoffroy B., Hervy J.P. \& Lebbe J. (1994). - Logiciel d'identification " Glossine Expert ». Manuel illustré d'utilisation. Editions ORSTOM, Paris.

D'après:

- Ministère de La COOPÉRATION ET du développemEnt \& IEMVT-CIRAD (1990). - Fiches techniques d'élevage tropical, $\mathrm{N}^{\circ} 1$, mars.

- CUISANCE D. (1989). - Le piégeage des tsé-tsé. Etudes et synthèses de l'IEMVT, Nº 32.

FIG. 1 (suite)

Quelques types de pièges et d'écrans à glossines 
Pour les glossines de galeries forestières, le meilleur rapport efficacité/coût semble obtenu avec le piège monoconique «Vavoua » et l'écran de Laveissière et coll. Pour les glossines de savanes, l'écran de Mérot-Filledier associé à l'acétone et au 1-octen-3-ol semble actuellement le plus recommandable.

\section{Pièges et écrans en usage en Afrique orientale et australe}

\section{Le piège cubique de Flint (Zimbabwe)}

C'est un cube $(0,9 \times 0,9 \mathrm{~m})$ de tissu bleu monté sur une armature métallique avec une entrée sur un côté, l'intérieur étant partiellement noir. Une pyramide de tulle dirige les glossines vers la cage située au-dessus. Ce piège est conçu pour les enquêtes sur les glossines savanicoles ( $G$. pallidipes, $G$. m. morsitans).

\section{Les pièges $N G-2 B$ et $N G-2 G$ de Brightwell et coll. (Kenya)}

Ils sont constitués de deux parois verticales en tissu bleu en $\mathrm{V}$ tendues entre trois piquets avec deux écrans noirs, l'un au-dessus de l'entrée et l'autre au fond à l'intérieur. Ils sont surmontés d'un cône en tulle moustiquaire et d'un sac de capture (matière plastique). Le modèle NG-2G comporte un panneau latéral bleu sur un côté. Il vise les glossines savanicoles d'Afrique orientale. Son faible coût permet un usage dans la lutte.

\section{Le piège «Epsilon » (Zimbabwe)}

C'est un prisme de tissu bleu avec un écran noir à l'intérieur et au fond. Il est destiné aux enquêtes sur les glossines savanicoles (G. pallidipes, G. m. morsitans).

\section{L'écran Vale (Zimbabwe)}

Le modèle standard est constitué d'un écran pivotant de tissu noir flanqué de deux panneaux de tulle ( $G$. pallidipes, $G$. m. morsitans). Dans un modèle plus récent, il n'y a plus de tulle moustiquaire : l'écran est un simple morceau de tissu noir $(1 \times 1,7 \mathrm{~m})$ imprégné de deltaméthrine. Ce modèle est largement utilisé dans de vastes campagnes en Afrique australe.

Les insecticides associés ou non à ces leurres sont tous des pyréthrinoïdes car un contact d'une ou de quelques secondes avec ces produits entraîne un effet létal ou une paralysie et une chute au sol de la glossine qui subit alors, avant de pouvoir éventuellement récupérer, l'effet des prédateurs (surtout des fourmis).

La deltaméthrine $(0,3 \%)$ provoque une mortalité des glossines (supérieure à $70 \%$ ) pendant 200 jours au moins. A $0,4 \%$, une seule imprégnation annuelle semble suffisante. La lambdacyalothrine et l'alphacyperméthrine, en particulier avec des formulations huileuses, semblent également d'excellents produits.

Les produits olfactifs connus et utilisables actuellement sont en nombre relativement limité et ne sont efficaces que pour quelques espèces de glossines, essentiellement du groupe morsitans (glossines de savanes) comme G. pallidipes et G. morsitans.

En particulier pour G. pallidipes, on utilise l'acétone diffusant à partir d'un flacon en verre muni d'un bouchon percé (100 à $150 \mathrm{mg} / \mathrm{h})$ ou le butanone $(15 \mathrm{mg} / \mathrm{h})$ associé à un mélange de phénols et de 1-octen-3-ol conditionnés dans un sachet de polyéthylène scellé (3-n-propyphénol/1-octen-3-ol/4-méthyl-phénol dans un rapport 1/4/8) à travers les parois duquel il diffuse. Le nombre de captures ainsi réalisées est multiplié par 10 ou 20 pendant de nombreux mois (193). L'urine de bovidés (qui contient des phénols) en association avec l'acétone donne un accroissement comparable des captures. 
Les résultats sont également intéressants, mais dans une moindre mesure ( 3 à 5 fois plus de captures), pour G.m. morsitans en utilisant les mêmes produits sauf le 4-méthylphénol, et pour $G$. $m$. submorsitans (3 à 7 fois plus de captures) en employant l'acétone $(100 \mathrm{mg} / \mathrm{h})$ et le 1 -octen-3-ol $(0,5 \mathrm{mg} / \mathrm{h})$.

Les améliorations sont pour le moment très médiocres ou inexistantes pour les glossines du groupe palpalis (galeries forestières) et du groupe fusca (glossines forestières).

L'emploi de produits olfactifs permet de réduire considérablement la densité d'implantation des leurres qui est actuellement de un à deux pièges par kilomètre carré pour $G$. pallidipes (écrans noirs pivotants imprégnés d'insecticides) et de quatre pièges par kilomètre carré pour G. m. morsitans au Zimbabwe. L'élimination totale de G. pallidipes a été obtenue dans certaines régions du Zimbabwe (191).

L'emploi de pièges NGU non imprégnés d'insecticide se fait à une densité de deux à huit pièges par kilomètre carré au Kenya $(23,55)$.

Pour les glossines riveraines (groupe palpalis), l'implantation le long du réseau de galeries forestières se fait à une densité d'un écran (type Laveissière) imprégné d'insecticide tous les 200 mètres. En zone forestière, la densité d'écrans (type "Vavoua ») dans les plantations de café varie de 0,5 à 4,5 écrans par hectare dans un foyer de maladie du sommeil (41 000 écrans insecticides mis en place) $(102,103)$.

Dans certains pays, les services de lutte contre les tsé-tsé s'occupent exclusivement de l'implantation des leurres et ont la totale maîtrise des opérations (80 000 écrans sont en place au Zimbabwe [Vale, communication personnelle], 10000 pièges «Vavoua » en Côte d'Ivoire) (44). Dans la plupart des pays, l'objectif est de faire prendre en charge techniquement et financièrement cette méthode de lutte par les populations locales afin de maintenir dans le temps et dans l'espace la forte baisse de densité des glossines obtenue. Ceci suppose que les leurres soient de plus en plus simples, robustes, peu onéreux, à faible maintenance et le plus efficaces possible.

Cette stratégie est appliquée en République Centrafricaine chez des éleveurs Mbororo pour la protection des abreuvoirs à bétail (36) ainsi qu'au Kenya chez les Masaï (23).

Chez les éleveurs, la participation est fonction de la pression des glossines, de la sédentarité des populations, des systèmes fonciers locaux, du niveau d'organisation, de l'engagement agricole, de la concentration du cheptel, etc. (93).

Les avantages des méthodes de piégeage sont nombreux :

- simplicité, accessibilité à des non-spécialistes,

- efficacité et rapidité,

- intérêt économique (en général, ces méthodes sont moins chères que les techniques d'épandages insecticides),

- absence d'effet nocif direct sur l'environnement,

- intégration assez facile à d'autres méthodes,

- possibilité d'étalement dans le temps de la mise en œuvre,

- polyvalence d'action (lutte et protection).

Des inconvénients freinent cependant leur mise en œuvre :

- efficacité n'aboutissant généralement pas à l'éradication du vecteur,

- vulnérabilité du matériel (vol, eaux, feux, vent, fauves), 
- contraintes de surveillance et d'entretien,

- motivation insuffisante des populations impliquées.

\section{Le cas du bétail imprégné}

L'utilisation du bétail imprégné d'un pyréthrinoïde comme piège « vivant », à la fois contre les glossines $(18,186)$, les autres diptères piqueurs (stomoxes, tabanides, hippobosques) et les tiques, peut être plus attirante pour l'éleveur qui préfère souvent prêter attention à ses animaux plutôt qu'à des leurres. Les formulations pour on (applications topiques dorsales) sont en particulier plus appréciées (18) mais elles ne sont valables que pour combattre des glossines très inféodées au bétail. Elles sont évidemment moins efficaces en présence d'hôtes nourriciers sauvages et lorsque le bétail ne pénètre pas tous les biotopes infestés de glossines. Cette méthode implique une relative sédentarité des éleveurs ainsi qu'une discipline de groupe pour que la majeure partie des troupeaux d'une région soit traitée régulièrement (tous les deux à trois mois) et de façon continue, ce qui reste indispensable. Le coût devient alors un facteur limitant.

Le fait que cette méthode agisse sur les tiques peut être un avantage, mais dans certaines conditions également un désavantage, car l'application continue et intensive d'un acaricide empêche l'installation d'une situation de stabilité endémique envers les maladies transmises par les tiques et peut rendre le bétail vulnérable à l'égard de ces maladies.

Toutes ces méthodes alternatives sont en progrès ; elles sont des outils indispensables dans la lutte contre les glossines en zone humide. Mais aucune n'est à elle seule capable d'assurer une polyvalence d'action vis-à-vis de plusieurs espèces de glossines à la fois et pour différentes situations d'élevage. Par contre, utilisées conjointement (lutte intégrée), elles peuvent réduire de façon économique et écologique le risque trypanosomien à un niveau compatible avec une chimiothérapie modérée du bétail sensible (36).

\section{STOMOXYINAE}

\section{Lutte écologique}

La lutte écologique contre les stomoxes fait appel à l'aménagement des élevages bovins, dans le but d'éviter notamment de laisser à disposition des mouches des sites favorables de ponte.

Les deux principales espèces, Stomoxys calcitrans et Stomoxys nigra pondent respectivement dans le fumier et dans les amas de matière végétale en décomposition comme les feuilles de canne à sucre accumulées entre les rangs après la coupe. L'élimination (par brûlage ou par enfouissement) de cette matière organique peut diminuer les populations de cet insecte piqueur (118).

Au Maryland, Schmidtmann (171) a remarqué que les $S$. calcitrans sont plus nombreux dans les batteries à veaux construites au niveau du sol avec une litière de paille que dans celles surélevées recevant de la sciure de bois et recommande donc ce dernier type de litière.

En Floride, dans les fermes laitières, les tas d'ensilage sont le principal site de ponte de $S$. calcitrans, nettement plus utilisés par cette espèce que le fumier ou les refus de foin (67).

Pour limiter la ponte dans ces sites, Easton (50) recommande de couvrir hermétiquement les tas d'ensilage avec des bâches de polyéthylène noires et d'épandre 
le fumier sur les champs le plus souvent possible en évitant son accumulation dans la ferme à proximité des animaux.

\section{Lutte biologique}

\section{Parasitoïdes}

Il s'agit pour la plupart d'entre eux, de petits hyménoptères qui pondent un ou plusieurs œufs dans les larves ou les pupes des diptères et les tuent lors de leur développement.

En Floride, $23 \%$ des pupes de S. calcitrans sont naturellement parasitées, essentiellement par Spalangia cameroni et Muscidifurax; Spalangia endius et Spalangia nigroaenea sont plus rares (67).

Le lâcher de grandes quantités de $S$. endius dans des élevages de Floride contrôle efficacement les pullulations de stomoxes (122). Les espèces présentes au Kansas sont S. nigroaenea, S. cameroni, Muscidifurax raptor et Muscidifurax zaraptor (66). Dans cet état des Etats-Unis d'Amérique, le lâcher de $50 \mathrm{~S}$. cameroni par bovin et par semaine réduit l'émergence des mouches de $95 \%$ à $20 \%$ (64); le lâcher de 50 S. nigroaenea par bovin et par semaine réduit également fortement le nombre de diptères présents par rapport aux élevages n'ayant pas fait l'objet de lâchers de parasitoïdes.

Au Kansas et dans le Nebraska, Greene (65) note que $S$. nigroaenea et $M$. raptor sont les parasitoïdes les mieux adaptés à $S$. calcitrans. Cet auteur considère que le lâcher de 100 parasites par bovin rapporte, en termes de production de viande, $260 \%$ du coût des lâchers.

En Californie, sept parasites infestent 13 à $20 \%$ des pupes (114); des lâchers de $S$. endius, Muscidifurax raptorellus et $M$. zaraptor dans un élevage laitier produisent un faible parasitisme des pupes de $S$. calcitrans, mais supérieur toutefois à celui constaté dans un élevage témoin.

Le lâcher mensuel de 350000 M. zaraptor n'entraîne pas d'effet visible sur l'abondance des stomoxes (113).

Dans des élevages laitiers de l'état de New York, Smith et Rutz (175) ont isolé 11 espèces de parasites de pupes sentinelles de $S$. calcitrans. Les plus fréquents sont $M$. raptor et Phygadeuon fumator.

Au Maryland, diverses méthodes de lutte intégrée incluant piégeage, pulvérisation de pyréthrines et lâcher de parasitoïdes ont été testées contre $S$. calcitrans; l'effet maximum a été obtenu avec un dispositif combinant piégeage (piège électrique et piège pyramidal) et pulvérisation. Le parasitoïde $M$. raptor infeste préférentiellement les pupes de mouches (116).

Au Zimbabwe, Trichopria painteri (Diapriidae) peut parasiter de 86 à $100 \%$ des pupes de $S$. calcitrans s'il est l'objet de lâchers massifs et réguliers (83).

A Maurice, où les pullulations de $S$. nigra limitent considérablement les possibilités de développement de l'élevage bovin, un certain nombre de parasitoïdes naturels contrôlent cependant les populations de stomoxes. Les espèces suivantes semblent avoir existé avant toute introduction : trois Pteromalidae, Spalangia sp., S. cameroni et S. nigroaenea, un Staphylinidae, Aleochara puberula et un Diapriidae, Trichopria sp. Le parasitisme par ces espèces n'a pas été évalué de façon précise mais semblait toucher $13 \%$ des pupes en 1967 (118). 
A la Réunion, avant toute introduction, un Staphylinidae, un Trichopria et un Spalangia parasitent $21 \%$ des pupes, la dernière espèce étant, de loin, la plus abondante (N. Barré et L. Bouillot, communication personnelle).

A Maurice depuis 1966, divers parasitoïdes ont été importés ou produits sur place et lâchés. Il s'agit essentiellement de Tachinaephagus (Encyrtidae) et de Trichopria (Diapriidae) lâchés dans les champs de cannes, sites de ponte de S. nigra.

En 1976, le taux de parasitisme des pupes par ces deux espèces était de $2 \%$ à $72 \%$ selon les localités. Tachinaephagus stomoxicida, une espèce importée d'Ouganda, s'avère avoir un impact beaucoup plus important que Trichopria $(62,119)$.

Toutes les espèces de parasitoïdes ne s'implantent pas dans toutes les situations écologiques. Ainsi, des pupes parasitées par divers parasitö̈des : Spalangia, Muscidifurax, Pachycrepoideus, Sphegigaster, ont été importées en 1969 en NouvelleZélande pour lutter contre Musca domestica et $S$. calcitrans ; cinq ans après, seuls S. cameroni, S. endius et Muscidifurax uniraptor s'étaient établis (110).

\section{Parasites et pathogènes}

Les agents pathogènes des stomoxes utilisables en lutte biologique sont mal connus (145). Des champignons (N. Barré et L. Bouillot, communication personnelle) (63), des bactéries (196) et des nématodes (63) ont été isolés de stomoxes chez lesquels ils produisent des taux de mortalité très variables.

Aucun de ces agents pathogènes, bioagents de contrôle potentiels, n'a été expérimenté dans des conditions naturelles.

\section{Lutte génétique}

Easton et Catangui (51) utilisent pour la technique du mâle stérile un chimiostérilisant, le bisazir, et obtiennent une stérilisation totale des adultes par immersion des pupes pendant 90 min dans une solution à $1 \%$.

Aux îles Vierges, Labrecque et coll. (97), ainsi que Paterson et coll. $(142,143)$ ont soumis des $S$. calcitrans à une dose de $20 \mathrm{~Gy}$ de rayons gamma, dose qui réduit la compétitivité des mouches traitées de $15 \%$; toutefois, ces mouches, lâchées en masse sur l'île (500 000 mouches par jour sur $2 \mathrm{~km}$ pendant 18 mois) réduisent la population sauvage de $50 \%$.

Cette technique jointe au lâcher du parasitoïde $S$. endius réduit la population de $99,9 \%$. L'éradication ne peut être obtenue en raison de la présence de foyers de ponte isolés ou de l'immigration de mouches venant d'îles voisines.

Ces divers succès quant à l'efficacité de la technique laissent entrevoir qu'une action soutenue faisant appel aux mâles stériles pourrait, dans des périmètres isolés, aboutir à une éradication des stomoxes.

\section{Lutte mécanique}

A Maurice, le ministère de l'agriculture a développé des pièges adaptés à l'élevage pratiqué dans cette île. Les bovins sont tenus enfermés dans des huttes de paille qui laissent pénétrer de grandes quantités de $S$. calcitrans et surtout de $S$. nigra. Ces étables sont pourvues d'une petite ouverture pour la lumière. Les pièges (exit trap) consistent en cubes de $30 \times 30 \times 30 \mathrm{~cm}$ à armature métallique pourvus d'un cône d'entrée formant une nasse appliquée sur les fenêtres de l'étable. Les stomoxes, attirés par la lumière, se prennent dans le piège en voulant sortir de l'étable après leur repas de sang sur les bovins (119). 
L'adjonction de sources lumineuses fluorescentes noires et/ou bleues n'augmente pas l'attractivité des pièges (146). Divers types de pièges ont été mis au point (Fig. 2), souvent plus pour échantillonner les stomoxes que pour avoir un impact sur leurs populations : piège Williams (201), heifer-baited trap (202), sticky fly trap (50), cylindrical Alsynite plastic trap (24). II s'agit en général de feuilles de plexiglas pourvues d'une surface adhésive, soit plane et disposée en croix, soit courbée en cylindre. Leur efficacité a été comparée par Hogsette et Ruff (79) : à surface de piège comparable, le piège cylindrique est dix fois plus efficace que le piège Williams.

Au Kenya où 11 espèces et sous-espèces de stomoxes ont été identifiées, Mihok (115) a testé plusieurs pièges munis de tissus de différentes couleurs imprégnés de diverses substances attractives. Les meilleurs résultats sont obtenus avec le piège « Vavoua » (voir ci-dessus les pièges à glossines), muni d'un tissu bleu associé à un produit olfactif (0,5-1 mg/h de 1-octen-3-ol). L'acétone, l'urine et les déjections d'animaux ne sont pas attractifs. Holloway et Phelps (80) identifient également le 1-octen-3-ol comme un attractif pour les stomoxes. Vale (190) indique que le dioxyde de carbone $\left(\mathrm{CO}_{2}\right)$ est un attractif des Stomoxyinae. Des dispositifs avec émission de ce gaz pourraient accroître l'efficacité des pièges.

Au Zimbabwe, des pièges en tissu bleu attirent trois fois plus de S. calcitrans et de S. nigra que les pièges en alsynite et plus de vingt fois plus que les pièges Williams (80).

Dans le Maryland, Pickens (147) et Pickens et Mills (148), utilisant un piège pyramidal blanc et jaune muni d'une grille à alimentation solaire pour électrocuter les insectes, capturent en moyenne 1190 et jusqu'à 4000 S. calcitrans par jour et par piège.

Pour résumer, il existe un large éventail de mesures permettant de lutter contre les stomoxes. Elles sont basées essentiellement sur la suppression des sites de ponte par un épandage régulier des fumiers et la couverture des ensilages. Les lâchers de parasitoïdes ont prouvé leur efficacité dans divers pays. Tout comme la technique des mâles stériles, c'est une méthode dont la généralisation serait aisée compte tenu de la maîtrise obtenue dans l'élevage des stomoxes. Des recherches complémentaires devraient être conduites pour identifier et tester des agents pathogènes d'insectes. Le piégeage est efficace avec les exit traps de l'île Maurice ou les pièges adhésifs en cylindre utilisés aux Etats-Unis d'Amérique. Toutes ces méthodes, mises en œuvre seules ou combinées, auront un impact d'autant plus important qu'elles seront appliquées en commun par les éleveurs d'une même région.

\section{TABANIDES}

La lutte contre les tabanides fait essentiellement appel à l'utilisation d'insecticides mais elle peut être complétée par des pratiques agronomiques, le recours à certains prédateurs et pathogènes et le piégeage.

\section{Lutte écologique}

Les femelles de taons pondent leurs paquets d'œufs sur la végétation des prairies dans les milieux humides. Une fois éclose, la larve tombe au sol, s'enfonce dans le substrat où elle se nourrit de larves d'insectes, de vers et d'arthropodes. Son développement dure de six mois à trois ans selon les espèces et la zone géographique (166).

Les stades larvaires nécessitant pour leur développement un sol meuble et humide, le drainage, l'assèchement des ruisseaux et des mares, le débroussaillage des berges et la suppression des effluents d'étables constituent des méthodes d'appoint efficaces $(7,166)$. 
Ces mesures ne sont pas applicables lorsque ces gîtes larvaires sont nombreux, dispersés et étendus comme c'est le cas dans la plupart des régions tropicales humides (160).

Par ailleurs, la présence de zones embroussaillées permet aux animaux de se protéger du harcèlement des insectes aux heures de forte agressivité et leur suppression exposerait les animaux aux piqûres des insectes (48).

En Guyane existent deux genres principaux : Tabanus et Cryptotylus. Le premier est diurne et actif surtout dans la matinée et en fin d'après-midi, le second est crépusculaire et pique les animaux pendant une trentaine de minutes à l'aube et au crépuscule $(158,160)$. Les taons sont des espèces exophiles. Cette caractéristique jointe à leur rythme d'activité permet de penser qu'en période de pullulation (août à décembre en Guyane par exemple, 156), le retrait des animaux le jour et le pâturage de nuit pourraient limiter l'impact des ces diptères piqueurs. De même, ceux-ci sont plus abondants à proximité des forêts galeries et de la lisière de la forêt ombrophile (160). Le pâturage dans des sites éloignés de ces habitats devrait contribuer à limiter l'infestation des animaux.

\section{Lutte biologique}

\section{Prédateurs}

De nombreux prédateurs vertébrés et invertébrés consomment occasionnellement des adultes ou des larves de taons $(88,154,159)$. C'est le cas des guêpes de la famille des Sphecidae en Guyane $(156,157,158,159)$ ou en Louisiane $(163)$, qui capturent des adultes.

L'utilisation pratique de ces ennemis naturels, dont le rôle est probablement faible, n'est pas aisée mais il peut être prévu par exemple de favoriser leur présence en disposant des tas de sable où ils viendraient établir leur nid.

\section{Parasitoïdes}

Les œufs des taons sont parasités par des microhyménoptères des genres Telenomus et Trichogramma. Ils peuvent être très fréquents, attaquant jusqu'à $80 \%$ des œufs en Guyane (160). Parman (141) a utilisé Telenomus emersoni pour lutter contre Tabanus hyalinnipennis au Texas. Des pontes naturellement parasitées ont été massivement introduites dans cet état. Le parasite a persisté une dizaine d'années et a gagné 20 comtés, atteignant parfois $97 \%$ des pontes. Malgré ces résultats très encourageants, ce travail est resté sans suites. Les nymphes peuvent être parasitées par des petits hyménoptères des genres Trichopria et Diglochis. Ces derniers peuvent parasiter jusqu'à $20 \%$ des nymphes $(155,159)$. La difficulté d'un élevage de tabanides rend cependant problématique la production à grande échelle de tels agents de contrôle biologique.

\section{Pathogènes}

Les champignons ont été les agents les plus étudiés, essentiellement en ex-Union Soviétique, pour lutter contre les taons au stade larvaire. Des essais de faisabilité ont même été tentés avec deux espèces: Metarhizium anisopliae (170) et Coelomomyces milkoi (9). Elles ont un effet létal sur les larves, la seconde espèce tuant jusqu'à $25 \%$ des larves six mois après inoculation et entraînant une forte diminution des taons l'année suivante. Ces essais n'ont pas été poursuivis malgré les résultats prometteurs obtenus.

Un autre champignon, Entomophtora tabanivora, rare et peu contagieux (8), semble peu adapté à une utilisation en lutte biologique.

\section{Lutte mécanique}

De façon courante et traditionnelle, les éleveurs allument autour des aires de rassemblement de leur bétail des feux générateurs d'épaisses fumées pour écarter les tabanides et autres insectes piqueurs. 
Les techniques de captures de taons ont été l'objet de diverses expériences en régions néarctique $(164,165)$ et africaine $(5,192)$. Elles ont généralement été mises au point davantage pour la conduite d'études faunistiques que pour la capture et la destruction des tabanides.

Le piège le plus utilisé est dérivé du modèle Malaise-Stonville de Roberts (165) et du modèle de Catts (29). Le leurre (Fig. 2) est constitué de deux panneaux noirs placés sous une tente pyramidale en moustiquaire verte (H.R. Raymond, communication personnelle). Ce dispositif peut être ou non assorti d'une source de $\mathrm{CO}_{2}$ débitant $11 / \mathrm{min}$, gaz connu pour son effet attractif sur les taons $(75,82,164,205)$. Le $\mathrm{CO}_{2}$ améliore en effet très sensiblement le rendement du piège, mais fait malheureusement également augmenter la capture des guêpes prédatrices.

Divers pièges : Manitoba Canopy trap, New Jersey box trap (2), ont été mis au point. La couleur noire est attractive sur les taons ainsi que les émissions de $\mathrm{CO}_{2}$, d'octenol $(107,173)$ et d'ammoniac $(82)$. La réduction de la réflectance ultra-violette du tissu par un traitement spécial ( $U V$ killer) accroît significativement les captures (81).

Au Burkina Faso, Amsler et coll. (5) ont montré que les pièges à glossines de type NG, cubique de Flint ainsi que l'écran-piège de Gouteux-Noireau (non cité précédemment) sont cinq à neuf fois plus efficaces contre les tabanides que les pièges mono- et biconiques. Le méta-crésol et l'octenol accroissent les captures de 1,6 à 3 fois.

Les applications pratiques de ces pièges restent à démontrer. Leur efficacité peut être élevée si les pièges sont appâtés. En Guyane, H.L. Raymond (communication personnelle) capture en 2 h jusqu'à 350 taons par piège alimenté en $\mathrm{CO}_{2}$ contre 64 taons
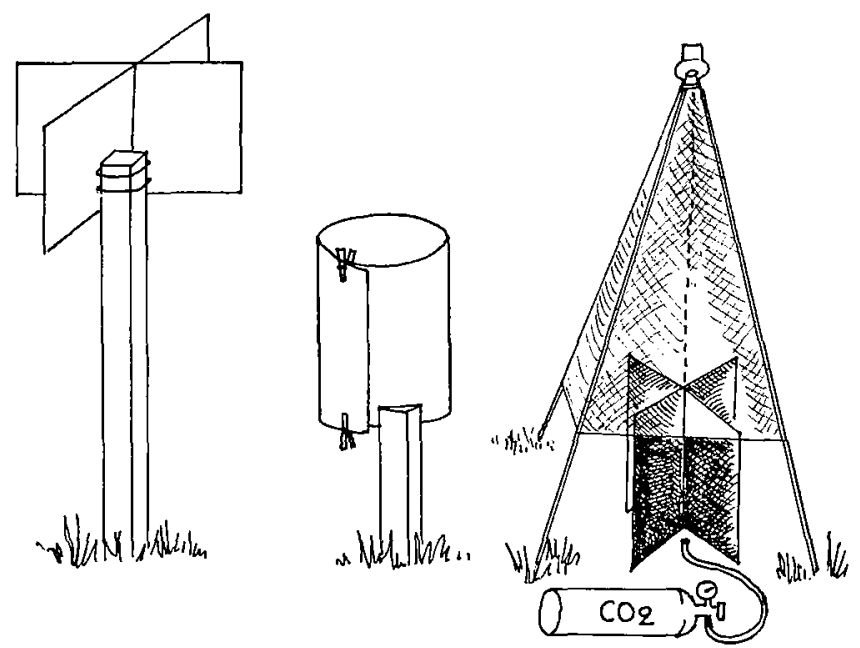

FIG. 2

\section{Pièges à stomoxes et tabanides}

De gauche à droite : piège Williams à stomoxes $(\mathrm{h}=1,30 \mathrm{~m})$ en panneaux d'alsynite couverts d'un adhésif ; piège cylindrique à stomoxes $(\mathrm{h}=0,50 \mathrm{~m})$, en alsynite enroulé couvert d'un adhésif ; piège Malaise à taons $(\mathrm{h}=1,80 \mathrm{~m})$ formé de deux panneaux noirs sous une tente pyramidale en moustiquaire 
par piège non appâté. Cependant le coût de l'approvisionnement en $\mathrm{CO}_{2}$ interdit son emploi comme moyen de lutte systématique contre les taons (H.L. Raymond, communication personnelle).

Pour conclure, il existe diverses méthodes de lutte agronomique et biologique contre les tabanides, mais leurs sites de ponte sont diffus, ce qui rend difficile un contrôle par drainage, assèchement et débroussaillage. L'élevage des tabanides n'est pas au point et la lutte par production de parasitoïdes ou par des méthodes génétiques n'est pour l'instant pas envisageable.

Le grand nombre d'espèces composant cette famille, ayant chacune ses exigences et son comportement, ne simplifie d'ailleurs pas la tâche des biologistes pour la mise au point de ces méthodes.

Le piégeage de ces insectes donne de bons résultats, surtout si les pièges sont munis d'une source odorante attractive. Le développement de systèmes simples et bon marché à des fins de contrôle plutôt que d'échantillonnage ou d'inventaire pourrait être une des solutions au problème des tabanides.

\section{NÉMATOCÈRES}

\section{Lutte écologique}

Les méthodes de lutte écologique contre les nématocères qui font appel à l'aménagement de l'environnement, ont été passées en revue dans une publication de l'Organisation mondiale de la santé (138). Les mesures pouvant être prises se situent dans les domaines suivants :

a) Eliminer les gîtes des nématocères : certains gîtes pré-imaginaux des moustiques $(59,166)$ et des cératopogonides $(89)$ peuvent être supprimés par des travaux de drainage ou des travaux de régularisation des berges des fleuves et des étangs, évitant la formation de mares résiduelles. Afin d'éliminer certains moustiques, on veillera à couvrir ou supprimer tout récipient d'eau pouvant servir de gîte temporaire. L'élimination des tas de détritus, des terriers de rongeurs ou le comblement des crevasses dans les murs extérieurs, gîtes potentiels des phlébotomes, contribuent à leur disparition.

b) Provoquer des changements d'environnement néfastes pour l'insecte : une action sur la végétation aquatique ou terrestre peut modifier le biotope de l'insecte (moustiques, simulies, phlébotomes ou cératopogonides) au point de le rendre hostile (153). Pour lutter contre les simulies ou moustiques, on peut, lorsque cela est possible, procéder à des assèchements périodiques des gîtes (par exemple par une variation du débit des rivières ou par l'irrigation intermittente des rizières). Une couche de deux à trois centimètres de billes en polystyrène empêche l'oviposition de Culex quinquefasciatus dans les fosses septiques. La régularisation de la pente d'un cours d'eau, le choix d'un type de barrage moins propice à la prolifération des larves $(38,152)$ ou la suppression d'autres supports utilisés par les larves peuvent réduire les populations de simulies.

c) Empêcher le contact entre l'insecte hématophage et son hôte : afin de protéger le bétail contre les piqûres des nématocères, on peut le mettre à l'étable durant les périodes d'activité des insectes ou l'asperger avec des produits répulsifs (diéthyltoluamide, citronnelle, diméthylphtalate, hexahydro-dibenzofurancarboxaldéhyde ou MGK) (11).

Dans certains pays, les éleveurs font des petits feux sur le lieu de stabulation du troupeau pour éloigner les insectes. 


\section{Lutte biologique}

Une vaste bibliographie sur les poissons carnivores et herbivores qui peuvent contrôler les larves des Culicidae par prédation ou par modification de l'habitat, est fournie par Ahmed et coll. (1). Une expérience faite à Rangoon a démontré que les larves de la libellule Crocothermis servilia sont capables de supprimer les larves d'Aedes dans les gîtes temporaires péridomestiques (162). D'autres prédateurs ont donné lieu à des lâchers massifs à partir d'élevages permanents et se sont révélés encourageants, comme les larves de moustiques appartenant au genre Toxorhynchites, qui se nourrissent d'autres larves culicidiennes partageant les mêmes gîtes (58).

Le nématode Romanomermis culicivorax parasite les moustiques et provoque une infection souvent mortelle pour les larves. L'élevage massif de ce parasite a permis sa commercialisation. Néanmoins, il n'est guère utilisé par les responsables de la lutte antimoustiques, probablement à cause de son prix.

Certaines souches de Bacillus sphaericus et de B. thuringiensis forment des spores contenant des endotoxines ayant une importante activité larvicide, respectivement envers les moustiques et/ou les simulies. Depuis que ces souches ont pu être isolées et multipliées à échelle industrielle, ces bactéries sont utilisées couramment dans la lutte contre les nématocères (43). L'intérêt de ces produits réside surtout dans leur spécificité, leur innocuité envers les organismes non-cibles et leur activité envers des insectes résistants aux insecticides classiques. Cependant, l'utilisation de ces bactéries pose aussi quelques problèmes. Les spores contenant les endotoxines précipitent facilement. Pour des larves se nourrissant à la surface de l'eau, l'efficacité du produit doit donc être améliorée en fixant le produit à des particules. Bien que la toxine soit très stable, la persistance de $B$. thuringiensis n'est pas très longue du fait de la sédimentation ; elle peut être améliorée par la fabrication de formulations à libération lente ou en introduisant les gènes codant pour la production des endotoxines dans d'autres micro-organismes (bactéries sporulantes) ou éventuellement dans des algues.

\section{Lutte génétique}

Plusieurs méthodes susceptibles de réduire le potentiel reproducteur des nématocères par une altération ou un remplacement du matériel héréditaire ont été développées dans le passé (stérilisation par rayonnement ou chimiostérilisant, stérilité parmi les hybrides issus d'un croisement entre espèces proches, stérilité due à une incompatibilité cytoplasmique entre différentes souches d'une espèce, introduction dans la population naturelle de gènes défavorables obtenus par des manipulations chromosomiques ou substitution d'une population à capacité vectorielle importante par une autre à capacité réduite ou nulle et occupant la même niche écologique). Bien que ces techniques soient probablement appelées à un grand avenir, aucune n'est vraiment opérationnelle actuellement à cause de leur extrême complexité $(38,166)$.

\section{Lutte mécanique}

Les couches mono-moléculaires (des amines aliphatiques ou des dérivés de l'alcool stéarique) sont des liquides tensioactifs, qui se répandent spontanément sur toute la surface de l'eau. Ces produits sont utilisés au niveau des gîtes des moustiques pour y tuer les larves et les pupes par asphyxie, de la même façon que les huiles minérales, qui ne sont cependant pas biodégradables à l'opposé des couches mono-moléculaires.

Dans les eaux stagnantes, les couches mono-moléculaires sont parfois mélangées aux souches de $B$. thuringiensis afin d'améliorer la dispersion et de contrecarrer la sédimentation de ce dernier. 


\section{Produits alternatifs}

L'incorporation de tourteaux de Neem (Azadirachta indica) dans le sol des rizières améliore la récolte et inhibe simultanément le développement des moustiques et des insectes ravageurs du riz grâce àux terpénoïdes qui se dissolvent dans l'eau (162).

Dans les élevages, où le purin s'accumule dans un bassin, celui-ci peut servir de gîte à C. quinquefasciatus ou autres moustiques. Dans ces conditions, certains régulateurs de croissance tels que le diflubenzuron, produits qui dérèglent la formation de la chitine ou la métamorphose, empêchent le développement des moustiques pendant quelques semaines (10).

\section{HIPPOBOSCIDAE}

En l'absence de moutons, les Melophagus ovinus issus de pupes tombées accidentellement par terre ne survivent qu'une huitaine de jours après leur éclosion. Puisque le stade pupal prend trois à cinq semaines, on ne considérera une prairie exempte de l'ectoparasite que deux mois après le départ des moutons.

\section{POUX ET PUCES}

\section{Lutte écologique}

Les poux ne peuvent pas se passer de leur hôte pendant plus de dix jours. L'infestation se développe par contact direct entre animaux ou de manière mécanique par les personnes qui soignent les animaux. La surpopulation dans l'étable ou une mauvaise hygiène favoriseront donc l'infection. La tonte des moutons est une mesure hygiénique de base.

Les larves des puces sont généralement très sensibles à la dessiccation. En maintenant l'humidité relative en dessous de $55 \%$ pendant plusieurs mois, le cycle de Ctenocephalides felis peut être interrompu (136).

\section{Lutte biologique}

Des souches de $B$. thuringiensis présentent un certain intérêt pour la lutte contre les poux. En Australie, des expériences à petite échelle ont démontré qu'une solution aqueuse de la souche WB 3S-16 serovar kurstaki (souche isolée sur toison de mouton) parvenait à réduire de $92 \%$ en sept jours et de $97 \%$ en six semaines le nombre de poux sur des moutons infestés (45).

Bairamlia fuscipes (Hymenoptera : Chalcididae) parasite les larves et les nymphes des puces. Certaines fourmis, des coléoptères et quelques acariens consomment les larves et les adultes des puces.

\section{Produits alternatifs}

Chez les puces, le développement des larves s'arrête après traitement du biotope larvaire avec des produits ayant une activité d'hormone juvénile, tels que le méthoprène (135), le fenoxycarbe ou le pyriproxyfène (47), ou après traitement avec des produits qui inhibent la formation de la chitine, tels que le diflubenzuron, la cyromazine ou le triflumuron (76). Ces produits ont une longue activité prophylactique : l'application de 2 à $10 \mathrm{mg}$ de méthoprène par $\mathrm{kg}$ de poids vif sur le pelage du chat empêche le développement des œufs de $C$. felis pendant au moins 43 jours. Soixante jours après le traitement du biotope larvaire à la dose de $6,5 \mathrm{mg}$ de méthoprène $/ \mathrm{m}^{2}$ ou de $23,7 \mathrm{mg}$ de 
fenoxycarbe $/ \mathrm{m}^{2}$, respectivement $70 \%$ et $100 \%$ des $C$. felis n'ont plus atteint le stade adulte (139). L'application de $32 \mathrm{mg}$ de pyriproxyfène $/ \mathrm{m}^{2}$ sur le sol inhibe le développement larvaire pendant trois semaines. Sur les tapis, le diflubenzuron à une dose de $53 \mathrm{mg} / \mathrm{m}^{2}$ a un effet similaire pendant une année. Sur le sol, l'effet prophylactique d'une dose de $3 \mathrm{~g}$ de diflubenzuron $/ \mathrm{m}^{2}$ est de un à six mois selon que le sol est à l'extérieur ou à l'intérieur (76). Le développement de C. felis sur le chat traité par voie orale avec une dose unique de lufenuron est inhibé pendant les sept semaines suivant le traitement (78).

L'acide borique $\left(2 \mathrm{~g} / \mathrm{m}^{2}\right)$, la poudre de talc, un extrait des graines de l'arbre de Neem (Azadirachta indica) et le D-limomène $\left(2,3 \mathrm{~g} / \mathrm{m}^{2}\right)$ ont également un effet larvicide sur C. felis.

Les poux sont reconnus sensibles au diflubenzuron et à la cyromazine mais l'élimination totale des poux n'est pas toujours obtenue $(19,105)$.

\section{ACARIENS}

\section{ACARIENS DES GALES}

Sarcoptes scabiei et Psoroptes spp. ne survivent pas dans une étable d'où les animaux ont été retirés pendant plus de 17 jours. L'isolement des malades, le respect des conditions d'hygiène élémentaire et une bonne alimentation sont des mesures à respecter.

\section{TIQUES}

\section{Lutte écologique}

La rencontre d'une tique et de son hôte semble être un événement fortuit. C'est en fait le résultat de processus complexes dépendant de la biologie propre de l'hôte et du parasite, mais aussi des caractéristiques du climat et des pâturages où ils cohabitent (12).

Les méthodes agronomiques de lutte vont consister à gérer la rencontre entre un hôte attractif d'une part et une tique pourvue des récepteurs et des capacités de locomotion pour le repérer et l'atteindre, d'autre part.

Il est possible d'influer sur les facteurs agissant sur les probabilités de contact hôteparasite :

- en modulant la charge en hôtes-proies,

- en diminuant la population de parasites, notamment en altérant ses chances de survie,

- en évitant la présence simultanée de l'hôte et de la tique en un même lieu lorsque leurs phases d'activité - ou pour la tique, de réceptivité aux stimuli de l'hôte coïncident,

- en évitant le détachement des tiques dans les zones fréquentées par les hôtes.

\section{Effet de la nature, de la densité et du comportement des hôtes}

La rencontre hôte-parasite est l'aboutissement de la période d'attente des tiques sur la prairie. Cet événement est indispensable à la pérennité et au renouvellement de la population. Il faut des hôtes disponibles et accessibles aux tiques. Dans ce cas, la phase 
d'attente sera d'autant plus brève que les chances de contact avec les hôtes seront plus nombreuses. Le taux de tiques trouvant un hôte est une des caractéristiques de l'espèce parasite qui dépendent, dans des conditions définies d'abondance de la ressource-hôte et pour des environnements particuliers, de l'aptitude de la tique à être stimulée par l'hôte, à le détecter, repérer sa position, à le rejoindre, à s'accrocher à lui et à s'y fixer $(126,181,182)$.

Parmi les facteurs abiotiques qui interviennent dans le processus, la température joue un rôle déterminant dans la levée de la quiescence et dans l'activité des tiques.

Parmi les facteurs biotiques, l'espèce hôte est fondamentale (taille, quantité de $\mathrm{CO}_{2}$ produite, vitesse, fréquence et amplitude des déplacements sur le substrat, rythme nycthéméral d'activité) ainsi naturellement que son abondance (14).

La détermination du taux de rencontre hôte-parasite est sans doute un des aspects de l'écologie de la tique les plus difficiles à mettre en évidence et à analyser. Ce taux est important à connaître car il va conditionner l'extraction par les animaux présents, des phases libres sur le pâturage et la rapidité de leur élimination si ces animaux sont détiqués de façon répétée, à un rythme ne permettant pas le détachement des femelles gorgées. C'est de lui aussi que dépend en grande partie la dynamique de la population parasite (accroissement, diminution, extinction), puisqu'il est évident que pour les parasites obligatoires que sont les tiques, l'absence d'hôtes favorables est fatale à l'espèce alors que leur abondance est gage de succès dans les limites du maintien de l'intégrité du couvert végétal.

Dans un essai conduit en Guadeloupe avec la tique trixène Amblyomma variegatum sur des parcelles expérimentalement infestées, 45 \% des tiques trouvent un hôte en une semaine lorsque la densité des animaux hôtes est d'un bovin par hectare. Pour un même temps de pâturage, cette proportion passe à $70 \%$ pour deux bovins par hectare et à $85 \%$ pour quatre bovins par hectare (13).

Ces taux, très proches de ceux obtenus en Australie avec Boophilus $(126,181)$, permettent de simuler pour chaque densité de bovins une cinétique d'assainissement des pâturages en fonction du temps de mise à l'herbe. Cela suppose, pour obtenir cet effet bénéfique, un détiquage concomitant des animaux et l'absence d'hôtes alternatifs (chiens, cervidés, antilopes, etc.) non détiqués.

A faible densité d'hôtes, les chances de rencontre hôte-parasite et donc de poursuite du cycle sont certes amoindries, mais en contrepartie, la couverture herbacée reste importante ce qui favorise une longue survie des tiques libres (182).

\section{Interventions limitant les chances de rencontre hôte-parasite}

\section{Retrait saisonnier des animaux}

Le retrait saisonnier des espèces hôtes aux époques de prolifération ou d'activité maximale s'est avéré efficace pour limiter l'infestation par Amblyomma americanum (150) et Ixodes ricinus (117).

Cette méthode pourrait être préconisée dans les pays tempérés ou tropicaux où les tiques ont un cycle marqué. La période de plus forte densité des tiques correspond cependant à celle où les ressources fourragères sont les plus abondantes, et le retrait des animaux à ce moment serait une mesure anti-économique.

\section{Retrait périodique à certaines heures de la journée}

Le but de cette mesure est d'éviter que les tiques ne se détachent sur la prairie et que les animaux ne pâturent aux heures où les tiques sont les plus actives. Pour 
A. variegatum, il a été montré en Guadeloupe (Fig. 3) que $90 \%$ des femelles, $95 \%$ des nymphes et $98 \%$ des larves se détachent entre 6 heures du matin et 18 heures (13).

Une mise au pâturage nocturne exclusive (entre 18 heures et 6 heures) réduirait l'infestation des pâturages (et donc des animaux après la mue ou la ponte) de 90 à $98 \%$ selon le stade. Il pourrait donc être envisagé de rentrer les animaux à l'étable au cours de la journée, les tiques détachées étant alors éliminées avec le fumier.

De plus, ces heures chaudes correspondent à celles où les tiques à jeun sont les plus actives : des pièges à $\mathrm{CO}_{2}$ disposés sur le pâturage permettent de capturer deux à vingt fois plus de tiques le jour que la nuit. Ce retrait nocturne diminuerait donc l'infestation des prairies par les tiques détachées de leurs hôtes et diminuerait l'infestation des animaux par les tiques à jeun à l'affût sur la prairie.

\section{Actions altérant la survie des tiques}

Action des facteurs climatiques

La survie des tiques, donc leur capacité d'infestation, est sensiblement diminuée lorsque le couvert végétal est ras, ce qui les expose directement aux facteurs climatiques : rayonnement solaire, température (Fig. 4). Un mois après l'éclosion, $100 \%$ des larves d' $A$. variegatum sont tuées si la moyenne des températures maximales a dépassé $32{ }^{\circ} \mathrm{C}(14)$, une température atteinte fréquemment en saison chaude au niveau du sol sous une faible couverture végétale.

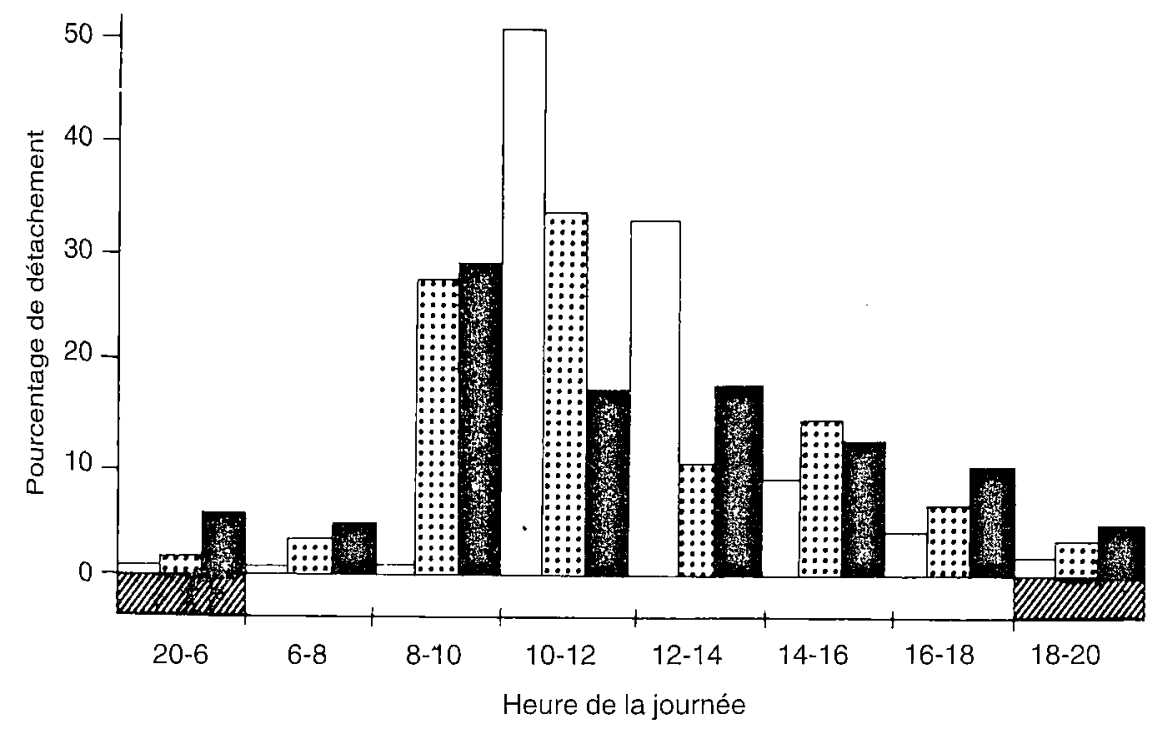

Larves $(n=1859)$

Nymphes $(n=1580)$

Femelles $(\mathrm{n}=302)$

FIG. 3

(C) Rev. Elev. Méd. vét. Payss trop.

Rythme de détachement des trois stades de la tique Amblyomma variegatum en fonction de l'heure de la journée

(D'après N. BARRÉ [13]) 

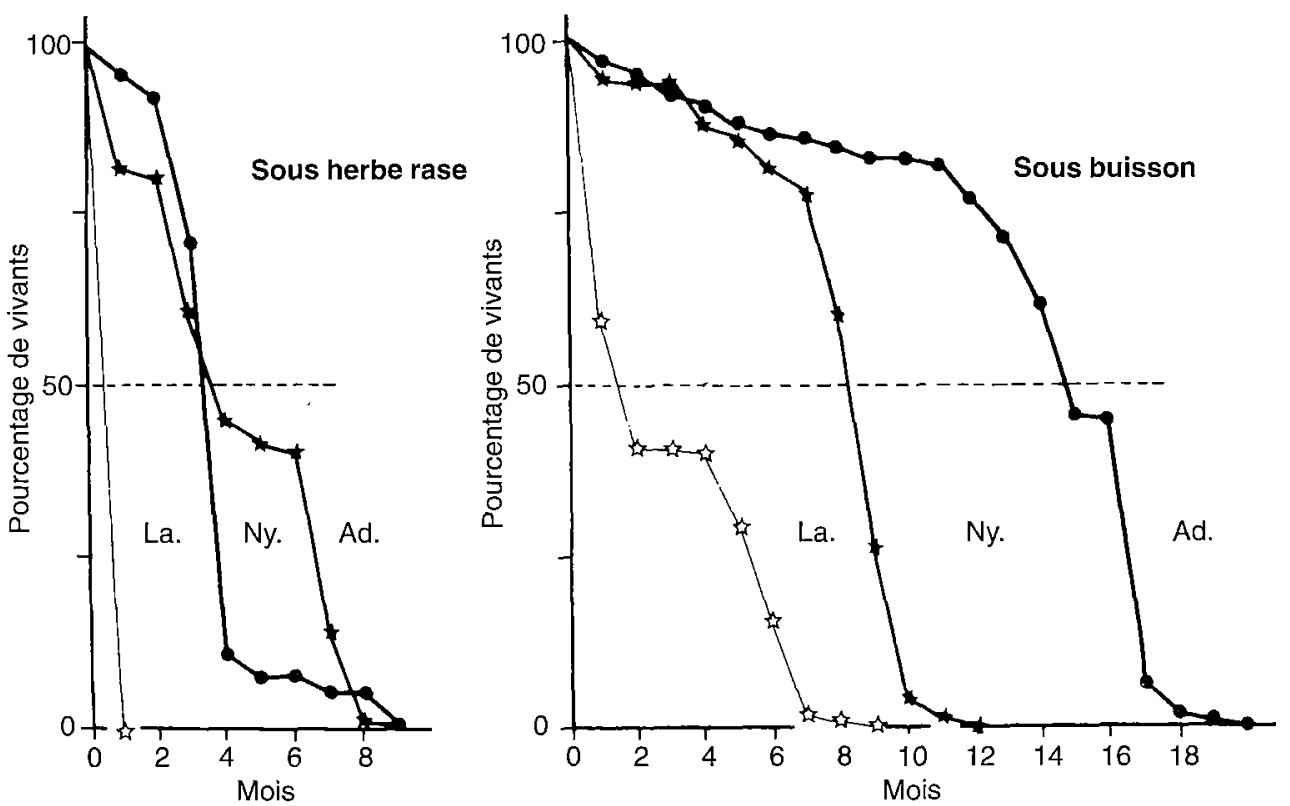

Fig. 4

(C) Rev. Elev. Méd. vét. Pays trop.

Courbes de survie des trois stades (La. : larves ; Ny. : nymphes ; Ad. : adultes) de la tique Amblyomma variegatum sur le sol de prairies en zone sèche de Guadeloupe dans deux situations microclimatiques

(D'après N. BARRÉ [13])

Par contre les buissons, les touffes d'herbes hautes, les zones ombragées sous les arbres ou sous la litière constituent des refuges où la survie peut être extrêmement longue.

Ainsi, en Guadeloupe, et dans ces conditions optimales, la survie des larves d'A. variegatum a pu atteindre 11 mois et celle des adultes 20 mois (14). Une aussi longue survie condamne, pour cette espèce dont les adultes sont très résistants aux facteurs climatiques, les méthodes agronomiques faisant appel à la mise en défens périodique des pâturages, appelée « rotation des pâturages ». Par contre, cette méthode est appliquée avec succès en Australie pour lutter contre Boophilus (198). L'élevage extensif qui y est pratiqué autorise des mises en défens de trois à quatre mois des parcelles, délai suffisant pour obtenir la mort de la quasi totalité des larves, seul stade infestant de cette espèce. Une telle rotation fait diminuer l'infestation dans des proportions équivalentes à celles obtenues par trois à quatre détiquages pour un troupeau maintenu en permanence sur la même parcelle $(71,72,198)$. Ce procédé permet de diminuer de façon déterminante le nombre des traitements, mais n'est probablement guère compatible, au moins en saison des pluies, avec une bonne gestion de la pousse de l'herbe.

Toujours en Australie avec Boophilus, Wharton et coll. (197), en pratiquant également une rotation de 3,5,4 et 4,5 mois, sont parvenus à ramener le nombre des détiquages à 7 contre 19 ou 20 lors d'une gestion conventionnelle des troupeaux. Ces résultats peuvent être atteints si les prairies sont homogènes, sans refuges où les tiques puissent se protéger de la rigueur des facteurs climatiques. 
Le labour, le broyage ou le brûlage des refus (200), constituent des mesures agronomiques d'appoint efficaces en exposant directement le sol, donc les tiques survivantes, à l'ensoleillement (121).

Cependant, Morel (121) considère que les effets directs et indirects du brûlage sur les tiques ne sont patents que dans les zones de savane humide ou au Sahel, en saison humide lorsque les tiques sont à l'affût sur la végétation. Les feux de brousse pratiqués en saison sèche alors que les tiques ont disparu ou sont dissimulées dans les anfractuosités du sol sont inefficaces $(121,127)$. Même en régions tempérées, le brûlage doit être considéré comme une méthode d'appoint, applicable seulement à certaines saisons contre certains stades de certaines tiques, en combinaison avec d'autres méthodes de lutte plus classiques.

Un désherbage chimique ou un surpâturage limité qui feraient disparaître temporairement la couverture végétale, combinés à un apport alimentaire complémentaire au bétail, auraient le même effet défavorable sur la survie des tiques, comme l'ont montré Wilkinson (200) pour Dermacentor andersoni et Milne (117) pour I. ricinus.

Les seules modifications de la couverture végétale dans les parcs de détente de l'Oklahoma : défrichement, tonte de l'herbe, retrait de la litière, ont permis de diminuer de $78 \%$ le nombre d'adultes d'A. americanum (123).

Les défrichements ont un effet défavorable pour les espèces de tiques qui dépendent pour leur survie de l'ombre d'arbres ou de grandes herbes, comme Amblyomma hebraeum (127) et Amblyomma cajennense (176). En périphérie de son habitat, le remplacement de la végétation buissonnante naturelle par des prairies de « kikuyu »a entraîné la disparition d'A. hebraeum (178).

La faune ou la microfaune associée au bétail peut contribuer à entretenir les tiques et entraver les opérations de lutte.

Certains rongeurs, insectivores et porcs-épics sont hôtes des immatures de tiques d'intérêt médical comme Dermacentor variabilis et $D$. andersoni au Canada (200). La destruction de ces hôtes, soit par empoisonnement, soit par labour et désagrégation des terriers (121), peut contribuer à la diminution de parasites infestant occasionnellement l'homme. Mais Wilkinson (200) note que les rongeurs et les musaraignes sont des prédateurs de tiques et que leur destruction irait à l'encontre du but fixé.

Les oiseaux interdisent toute lutte efficace contre Hyalomma marginatum et transportent également des immatures de nombreuses autres espèces comme ceux d'A. variegatum aux Antilles (15). C'est le cas également des reptiles qui servent au repas des stades pré-imaginaux de certains Amblyomma, Ixodes et Haemaphysalis (121).

\section{Installation de plantes fourragères toxiques pour les tiques}

De nombreuses graminées et légumineuses se sont montrées toxiques ou à action répulsive vis-à-vis des tiques dans des conditions expérimentales au laboratoire. Il y a cependant peu d'essais conduits en vraie grandeur permettant d'apprécier l'intérêt agronomique et vétérinaire de telles méthodes de lutte.

Certaines plantes comme les Desmodium sont couvertes de poils en crochets qui gênent le déplacement des tiques (104); d'autres sécrètent des substances à action toxique ou répulsive essentiellement pour les larves et les imagos qui montent sur la végétation à l'affût de leur hôte (Rhipicephalus). C'est le cas de graminées comme Melinis minutiflora connue des éleveurs colombiens pour ses effets bénéfiques sur la 
diminution de l'infestation des animaux par Boophilus, de Andropogon gayanus, Pennisetum clandestinum $(38,187)$ et surtout de légumineuses du genre Stylosanthes qui ont en outre de bonnes qualités nutritives. Stylosanthes viscosa et Stylosanthes scabra sont toxiques et détruisent toutes les larves de Boophilus microplus présentes en moins de 24 heures (183), une propriété que confirment Zimmerman et coll. (207) pour ces mêmes plantes sur des larves de Boophilus et d'A. variegatum. Norval et coll. (128) observent des résultats identiques avec Stylosanthes fruticosa, toxique et répulsif pour les larves de trois espèces de tiques africaines.

En Afrique, une Capparaceae (Gynandropsis gynandra) s'est montrée répulsive et toxique dans des conditions expérimentales pour Rhipicephalus sanguineus et A. variegatum (108). Pour des régions climatiques équivalentes, les zones où cette plante abonde naturellement ont beaucoup moins de Rhipicephalus pulchellus et Rhipicephalus simus que les zones où elle est absente.

De ces résultats, on peut conclure que la création de pâturages implantés avec une association de Melinis et de $S$. viscosa ou S. scabra pourrait avoir un effet déterminant sur le maintien des populations de tiques. Norval et coll. (128) considèrent cependant qu'on ne peut espérer un effet significatif sur les tiques que si ces plantes toxiques ou répulsives sont en peuplement pur ou sont fortement dominantes sur la prairie.

\section{Lutte biologique}

\section{Parasitoïdes}

Des essais d'élevages et de lâchers de Hunterellus hookeri (hyménoptère, Encyrtidés) ont été conduits aux Etats-Unis d'Amérique pour lutter contre D. variabilis (101), contre $D$. andersoni $(32,174)$ et en ex-Union soviétique pour contrôler 1 . ricinus (3). Tous ces essais se sont révélés efficaces dans un premier temps mais n'ont pas empêché par la suite les proliférations des espèces de tiques cibles, sans doute en raison d'une fertilité très supérieure des tiques comparée à celle des parasitoïdes.

Cependant, une récente enquête à Naushon Island, où Larrouse et coll. (101) avaient relâché $H$. hookeri en 1928 , a montré que le tiers des nymphes de la tique des daims Ixodes dammini étaient parasitées par $H$. hookeri, ce qui peut être attribué à la persistance des populations du parasitoïde lâché en 1928 (111).

\section{Parasites}

Des nématodes entomopathogènes de la famille des Hétérorhabditidae et des Steinernematidae se sont révélés pathogènes pour Boophilus annulatus $(60,112,169)$. Cependant 17 souches de nématodes ne se sont montrées pathogènes ni pour $B$. microplus ni pour $A$. variegatum (112). Ces nématodes naturellement présents dans le sol sont très utilisés comme bioagents en lutte biologique contre les insectes des cultures ; les possibilités de leur utilisation pour contrôler les tiques dans leurs phases libres sur la prairie restent à démontrer.

\section{Prédateurs}

Les tiques sont les proies exclusives ou occasionnelles de divers prédateurs dont l'impact ne peut être important que s'ils sont nombreux et spécialisés. Localement et dans certaines situations écologiques, des prédateurs comme les fourmis ou les poulets peuvent être des auxiliaires efficaces dans un programme de lutte intégrée.

En Louisiane, la fourmi Solenopsis invicta se nourrit de tous les stades d'A. americanum. Son impact serait tel que là où la fourmi est établie, la tique ne pourrait se maintenir $(25,73)$. Butler et coll. (27) indiquent qu'au Mexiquc, Solenopsis 
geminata détruit $63 \%$ des femelles gorgées de B. microplus de novembre à février. En Guadeloupe, cette fourmi peut attaquer et consommer jusqu'à $35 \%$ des larves gorgées d'A. variegatum, mais en moyenne seulement $9 \%$ de tous les stades déposés sur le sol (16). Son impact global est jugé modeste sur cette espèce de tique, peut-être en raison des capacités de cette dernière à produire une sécrétion cuticulaire répulsive pour les prédateurs (144).

En Australie, Iridomyrmex detectus, Pheidole megacephala et Aphaenogaster longiceps sont des prédateurs efficaces de $B$. microplus induisant une diminution de $50 \%$ du nombre des femelles gorgées (199).

Dans une expérimentation conduite à Cuba, $P$. megacephala a consommé en moyenne $40 \%$ des œufs de $B$. microplus mis à sa disposition (28); cette espèce s'est également montrée un prédateur naturel efficace contre $A$. cajennense (167).

La plupart des auteurs s'accordent à dire que les fourmis sont les agents biologiques les plus efficaces pour limiter la prolifération des tiques" $(16,27,121,199)$. Les inconvénients liés à la douleur provoquée chez l'homme par les piqûres de certaines de ces fourmis comme Solenopsis, la fire ant des anglo-saxons, condamnent leur utilisation systématique et les lâchers à grande échelle.

La seule prédation réellement importante par les vertébrés est sans doute celle provoquée par les pique-bœufs à bec jaune et à bec rouge (Buphagus africanus et Buphagus erythrorhynchus), oiseaux d'Afrique éthiopienne dont le régime comporte essentiellement des tiques (120). Bezuidenhout et Stutterheim (22) considèrent que ces oiseaux jouent un rôle non négligeable dans la limitation des populations de Boophilus decoloratus et $A$. hebraeum sur les ongulés domestiques et sauvages d'Afrique australe. Leur rôle est cependạt controversé puisqu'ils provoquent des plaies cutanées, porte d'entrée des agents des myiases.

Morel (121) et Mwangi et coll. (124), ont publié une longue liste d'oiseaux sauvages prédateurs effectifs ou potentiels de tiques. A priori, tout oiseau insectivore ou polyphage doit pouvoir consommer occasionnellement des tiques et d'autres ectoparasites pris au sol ou sur l'hôte.

Le poulet domestique est peut-être un des plus importants des oiseaux prédateurs. Newstead (125) constate une diminution de l'infestation par Boophilus de bovins maintenus dans des enclos auxquels les poulets ont accès. L'association bovins-poulets est fréquente dans les élevages traditionnels de tous les pays du monde. Morel (121) a observé des poulets picorant des tiques sur des bovins de troupeaux villageois et considère que cet oiseau est un bon auxiliaire de lutte. Au Kenya, Hassan et coll. (74) dénombrent jusqu'à 331 A. variegatum, Rhipicephalus appendiculatus et $B$. decoloratus dans des contenus stomacaux de poulets. Pour ces auteurs, le rôle des volailles comme agent bon marché de lutte biologique dans les programmes de lutte intégrée contre les tiques en Afrique doit être reconsidéré. En Guadeloupe cependant et également en élevage traditionnel, Barré et coll. (16) trouvent que les tiques constituent moins de $2 \%$ des proies des poulets.

\section{Pathogènes}

Plusieurs bactéries, champignons, rickettsies et virus ont soit été isolés de tiques, soit ont été étudiés lors d'infections expérimentales. Bien que certains d'entre eux se soient révélés pathogènes pour des tiques, jusqu'ici aucun n'a pu être utilisé sur le plan pratique. 


\section{Lutte génétique}

Deux méthodes sont théoriquement disponibles. L'une fait appel à la technique des mâles artificiellement stérilisés et relâchés dans la nature, l'autre à celle des hybrides stériles issus du croisement naturel entre deux espèces proches.

\section{Technique du mâle stérile}

Le succès de la campagne d'éradication de la lucilie bouchère aux Etats-Unis d'Amérique a contribué à la réputation de cette méthode qui n'est cependant pas transposable avec des résultats aussi déterminants à toutes les pestes agronomiques et vétérinaires. De nombreux auteurs ont tenté des essais sur des tiques, en particulier sur celles du genre Amblyomma dont les mâles restent fixés longtemps sur l'hôte où ils s'accouplent successivement à de nombreuses femelles. Cette particularité biologique fait de ces tiques de bonnes candidates à des techniques de lutte par stérilisation (46). La dose stérilisante non létale pour $A$. variegatum $(21), A$. americanum $(21,42)$ et A. hebraeum (177) se situe autour de 80 Gy.

D'autres espèces ont été l'objet d'essais : B. microplus (94), R. appendiculatus (151) et Alectorobius tholozani (57).

Cependant, la relative difficulté d'élever des tiques en masse et à bon marché, ainsi que leur mobilité quasi nulle obligeant à les disséminer dans tous les foyers d'infestation, jointes aux effets pathogènes des tiques stériles elles-mêmes, puisqu'il faut 10 fois plus de mâles stériles que de mâles sauvages pour que la méthode soit efficace (177), limitent considérablement ses applications pratiques, voire condamnent cette technique.

Technique des hybrides inféconds

Thompson et coll. (185) ont montré que les hybrides de B. microplus et $B$. annulatus étaient stériles quelle que soit la combinaison parentale, permettant de penser que cette technique pourrait être utilisée pour éradiquer des foyers d'infestation (140).

D'autres hybrides stériles ont été produits expérimentalement ou observés dans la nature entre espèces parapatriques : B. microplus et B. decoloratus (179), A. variegatum et $A$. hebraeum (161), Rhipicephalus zambeziensis et $R$. appendiculatus (194). Sutherst (180) estime que cette méthode peut être efficace si la proportion relative de l'espèce introduite est élevée. Le maintien de l'équilibre reste cependant très aléatoire et sa rupture peut conduire à l'élimination de l'espèce résidante par l'espèce introduite, ce qui ne ferait que déplacer le problème.

Il existe une situation dans laquelle le principe de la lutte par ce biais pourrait être envisagé : dans une population fermée comportant une espèce, l'adjonction de mâles d'une autre espèce (et de mâles seuls, ce qui rend cette technique irréaliste, voire très risquée) sexuellement plus compétitifs que les mâles de l'espèce présente (ce qui n'est pas le cas par exemple pour les accouplements entre les deux Amblyomma) pourrait conduire par hybridation à une extinction de la population cible. En théorie, cette méthode pourrait être recommandée pour tenter, par exemple, l'éradication de A. variegatum dans la Caraïbe en ayant recours au lâcher de mâles d'A. hebraeum.

\section{Lutte mécanique}

Les tiques sont attirées par le $\mathrm{CO}_{2}$ produit par leur hôte $(77,131)$. De plus, certaines espèces d'Amblyomma des herbivores produisent des phéromones d'agrégationfixation (172). Utilisant les composants phéromonaux, plusieurs auteurs ont tenté de mettre au point des pièges pour attirer les tiques sur le sol ou sur les animaux $(77,129$, $130,132,133,206)$. 
Pour des piégeages au sol, la difficulté est de maintenir une source artificielle émettrice de $\mathrm{CO}_{2}$. Par ailleurs, la distance d'action des phéromones est faible (quelques mètres au maximum), rendant hypothétiques les utilisations pratiques de tels dispositifs pour l'assainissement des prairies.

L'application directement sur des bovins au pâturage de phéromones d'agrégationfixation n'a pas permis à Barré et Pavis (17) de récolter sur les sites traités, plus d'A. variegatum que sur les sites équivalents d'animaux témoins.

Pour conclure, la lutte chimique et la lutte immunologique restent donc les méthodes de choix pour contrôler les populations de tiques. Cependant, la lutte agronomique, lorsqu'elle est basée sur des connaissances précises des besoins écologiques des espèces cibles, peut être économiquement justifiée. Elle a fait ses preuves en Australie contre Boophilus, aux Etats-Unis d'Amérique contre $A$. americanum et cette méthode pourrait être mieux valorisée contre des espèces comme $A$. variegatum dont on connaît bien les rythmes d'activité et de détachement.

Le recours à certains prédateurs serait localement bénéfique. S'il est malaisé de favoriser une prédation par les fourmis, l'utilisation de poulets peut, par contre, être très efficace pour lutter contre les tiques dans les élevages traditionnels. Sauf en ce qui concerne les tiques attirées par des phéromones et pour autant que cette attraction soit persistante, le piégeage de tiques, par définition peu mobiles, paraît illusoire. Le recours à des agents pathogènes, notamment à certaines bactéries ou champignons, nécessiterait certainement des investigations plus approfondies.

\title{
ECTOPARASITES OF ANIMALS: ECOLOGICAL, BIOLOGICAL, GENETIC AND MECHANICAL CONTROL METHODS. - D. Cuisance, N. Barré and R. de Deken.
}

\begin{abstract}
Summary: The use of insecticides is still the basic procedure for controlling most ectoparasites, but various methods are being developed to act in addition to, or in synergy with these products, so as to enhance the efficacy and reduce the adverse effects of insecticides, by contributing to ecologically acceptable strategies.
\end{abstract}

These methods are classified as ecological control (modification of the environment of the parasite), biological control (predation, parasitism, action of pathogens, etc.), genetic control (release of sterile males, hybridisation, genetic manipulations) and mechanical control (insect traps, use of repellents).

The application of such methods depends on the biological and ecological characteristics of the ectoparasite, and they may act directly or indirectly, affecting mortality and/or reproduction. The authors review the principal methods applicable to major groups of ectoparasites of veterinary interest.

Non-chemical methods are the subject of wide-ranging and promising research, particularly in view of recent developments in biotechnology.

KEYWORDS: Biological control - Control measures - Ecological control Ectoparasites - Genetic control - Mechanical control. 


\title{
ECTOPARÁSITOS DE LOS ANIMALES: MÉTODOS DE LUCHA ECOLÓGICA, BIOLÓGICA, GENÉTICA Y MECÁNICA. - D. Cuisance, N. Barré y R. de Deken.
}

\begin{abstract}
Resumen: Aun cuando el uso de insecticidas sigue siendo el modo de lucha básico contra la mayoría de los ectoparásitos, se están desarrollando varios métodos para actuar de manera complementaria o en sinergía con estos productos de manera de aumentar su eficacia y reducir sus efectos secundarios indeseables obteniendo estrategias ecológicamente aceptables.
\end{abstract}

Estos métodos se clasifican así: lucha ecológica (modificación del entorno del parásito), lucha biológica (rapiña, parasitismo, agentes patógenos, etc.), lucha genética (liberación de machos criados y esterilizados, hibridación, manipulaciones genéticas) y lucha mecánica (uso de trampas y productos repelentes).

Su aplicación respectiva depende de las particularidades biológicas y ecológicas del ectoparásito de que se trate, según permitan actuar directa o indirectamente sobre su mortalidad y/o su natalidad. Los autores pasan revista a los principales métodos aplicables en la lucha contra los ectoparásitos de interés veterinario.

Los métodos no químicos son actualmente objeto de investigaciones diversas y promisorias, en particular gracias a las biotecnologías recientes.

PALABRAS CLAVE: Ectoparásitos - Lucha biológica - Lucha ecológica Lucha genética - Lucha mecánica - Métodos de lucha.

\section{BIBLIOGRAPHIE}

1. Ahmed S.S., Linden A.L. \& CECH J.J. (1988). - A rating system and annotated bibliography for the selection of appropriate, indigenous fish species for mosquito and weed control. Bull. Soc. Vect. Cont., 13, 1-59.

2. Ailes M.C., Brown L.J., Church C., French D.P. \& Gale W. (1992). - Mechanical control of greenhead flies (Diptera: Tabanidae) in a marsh environment. $J$. med. Entomol., 29, 160-164.

3. Alfeev N.I. (1940). - The utilisation of Hunterellus hookeri for the control of the tick Ixodes ricinus with reference to peculiarity of their metamorphosis under conditions of Leningrad (cn russe). In Pavlovsky Second Conference on Parasitology Problems, novembre 1940. Izvestiya Akademii Nauk, Union soviétique, 23-25.

4. Alzieu J.P., Brard C. \& Personne F. (1993). - Les ectomyiases ovines. Bull. GTV, 5, 67-79.

5. Amsler S., Filledier J. \& Sanou G. (1994). - Attractivité pour les Tabanidae de différents pic̀ges à glossines en zone tropicale sub-humide. Rev. Elev. Méd. vét. Pays trop. (sous presse).

6. Anderson J., Mcleod L.J., Shipp E., Swan A. \& Kennedy J.P. (1990). - Trapping sheep blowflics using bait-bins. Altst. vet. J., 67, 93-97.

7. ANDERSON J.F. \& KNEEN F.R. (1969). - The temporary impoundment of salt marshes for the control of coastal deer flies. Mosq. New's, 29, 239-243. 
8. Anderson J.F. \& Magnarelli A. (1979). - Entomophtora tabanivora, a new pathogen in horse flies (Diptera: Tabanidae). I. Invertebr. Pathol., 34, 263-266.

9. ANdreEva R.V. (1976). - Etude de Coelomomyces milkoi Dudka et Koval, agent pathogène pour les larves de taons (en russe). Med. Parazit., 45, 212-218.

10. Axtell R.C., Rutz D.A. \& Edwards T.D. (1980). - Field tests of insecticides and insect growth regulators for the control of Culex quinquefasciatus in anaerobic animal waste lagoons. Mosq. News, 40, 36-42.

11. BABILONIA E.S. \& MAKI D.L. (1991). - Elevage de la lucilie bouchère stérile au sud du Mexique. Rev. mond. Zootech., ( $\mathrm{N}^{\circ}$ spécial), 36-41.

12. BARNARD R.D. (1986). - Aspects of the bovine host-lone star tick interaction process in forage areas. In Morphology, physiology, and behavioral biology of the ticks (J.R. Sauer \& J.A. Hair, édit.). Ellis Horwood Ltd., Chichester, 428-444.

13. BARRE N. (1988). - Mesures agronomiques permettant une diminution des populations de la tique Amblyomma variegatum. Rev. Elev. Méd. vét. Pays trop., 41, 387-393.

14. BARRE N. (1989). - Biologie et écologie de la tique Amblyomma variegatum (Acarina : Ixodina) en Guadeloupe (Antilles françaises). Thèse de Doctorat ès Sciences, Université d'Orsay, $267 \mathrm{pp}$.

15. Barre N., Garris G.I., Borel G. \& Camus E. (1988). - Hosts and population dynamics of Amblyomma variegatum (Acari: Ixodidae) on Guadeloupe, French West Indies. J. med. Entomol., 25, 111-115.

16. Barre N., Mauleon H., Garris G.I. \& Kermarrec A. (1991). - Predators of the tick Amblyomma variegatum (Acari: Ixodidae) in Guadeloupe, French West Indies. Expl appl. Acarol., 12, 163-170.

17. Barre N. \& PAvis C. (1992). - Essai d'attraction d'Amblyomma variegatum (Acarina : Ixodina) sur des bovins préalablement traités avec des phéromones d'agrégation-fixation et un acaricide pyréthrinoïde. Rev. Elev. Méd. vét. Pays trop., 45, 33-36.

18. Bauer B., Kaboré I., Liebisch A., Meyer F. \& Petrich-Bauer J. (1992). Simultaneous control of ticks and tsetse flies in Satiri, Burkina Faso, by the use of flumethrin pour on for cattle. Trop. Med. Parasitol., 43, 41-46.

19. BERNDT K.P. (1980). - Diflubenzurone zur Bekämpfung veterinärmedizinisch bedeutsamer Arthropoden. Mh. VetMed., 35, 73-77.

20. Betke P., Hiepe T., Müller P., Ribbeck R., Schultka H. \& Schumann H. (1989). Biologische Bekampfung vom Musca domestica mittels Ophyra aenescens in Schweineproduktionsanlagen. Mh. VetMed., 44, 842-844.

21. Beuthiner U. (1975). - Zur Sterile-Male-Release-Technique: Sterilisation durch v-Strahlen (Co) bei Amblyomma variegatum (Fabricius, 1794), Hyalomma anatolicum exacavatum (Koch, 1844) und Rhipicephalus appendiculatus (Neumann, 1901). Inaugural-Dissertation. Freie Universität, Berlin, 40 pp.

22. Bezuidenhout J.D. \& Stutterheim C.J. (1980). - A critical evaluation of the role played by the red-billed oxpecker Buphagus erythrorhynchus in the biological control of ticks. Onderstepoort J. vet. Res., 47, 51-75.

23. Brightwell R., Dransfield R.D. \& Kyorku C. (1991). - Development of a low-cost tsetse trap and odour baits for Glossina pallidipes and $G$. longipennis in Kenya. Med. vet. Entomol., 5, 153-164.

24. Broce A.B. (1988). - An improved alsynite trap for stable flies, Stomoxys calcitrans (Diptera: Muscidae). J. med. Enlomol., 25, 406-409. 
25. Burns E.C. \& MELACHON D.G. (1977). - Effect of imported fire-ant invasion on the lone tick population. J. Invertebr. Pathol, 14, 247-249.

26. Bussieras J. \& Chermette R. (1991). - Abrégé de parasitologie vétérinaire. Fascicule IV. Entomologie vétérinaire. Service de parasitologie. Ecole nationale vétérinaire, Maisons-Alfort, $163 \mathrm{pp}$.

27. Butler J.F., Camino M.L. \& Perrez T.O. (1979). - Boophilus and the fire ant Solenopsis geminata. Rec. Adv. Acarol., 1, 469-472.

28. Castineiras A., Jimeno G., Lopez M. \& Sosa L. (1987). - Efecto de Beauveria bassiana, Metarhizium anisopliae (Fungi Imperfecti) y Pheidole megacephala (Hymenoptera: Formicidae) contra huevos de Boophilus microplus (Acarina: Ixodidae). Revta Salud Anim., 9, 288-293.

29. CATTs E.P. (1970). - A canopy trap for collecting Tabanidae. Mosq. News., 30, 472-474.

30. Challier A. \& Laveissiere C. (1973). - Un nouveau piège pour la capture des glossines (Glossina: Diptera, Muscidae), description et essais sur le terrain. Cah. ORSTOM, série Entomol. méd. Parasitol., 11, 251-262.

31. Clarcke G.M. (1991). - Report on a sterile insect release trial for the control of the Old World screwworm fly, Chrysomya bezziana, in Papua New Guinea. Aust. vet. J., 68, 277-279.

32. COOLEY R.A. (1928). - Preliminary report on the tick parasite, Ixodiphagus caucurtei. In Seventh Biennial Report, Montana State Board of Entomology, 16-25.

33. CuisAnCE D. (1989). - Le piégeage des tsé-tsé. Etudes et Synthèses de l'IEMVT, N³2, Maisons-Alfort, $172 \mathrm{pp}$.

34. Cuisance D., Politzar H., Clair M., Sellin E., Taze Y., Bourdoiseau G. \& Fevrier J. (1980), - La lutte contre Glossina palpalis gambiensis Vanderplank par lâchers de mâles irradiés en Haute-Volta : étude de paramètres opérationnels. In Proc. Symposium on Isotope and Radiation Research on Animal Diseases and their Vectors. IAEA, Vienne, Autriche, 249-266.

35. Cuisance D., Politzar H., Merot P. \& Tamboura I. (1984). - Les lâchers de mâles irradiés dans la campagne de lutte intégrée contre les glossines dans la zone pastorale de Sidéradougou (Burkina Faso). Rev. Elev. Méd. vét. Pays trop., 37 (4), 449-467.

36. Cuisance D., Cailton P., Kota-Guinza A., Ndokoue F., Pounekrozou E. \& Demba D. (1991). - Lutte contre Glossina fuscipes fuscipes par piégeage chez les éleveurs Mbororo de République Centrafricaine. Rev. Elev. Méd. vét. Pays trop., 44 (1), 81-89.

37. Cunningham E.P. (1992). - Le programme d'éradication de la lucilie bouchère d'Afrique du Nord. Rev. Elev. Méd. vét. Pays trop., 45 (2), 115-118.

38. CurTis C.F. (1990). - Appropriate technology in vector control. CRC Press Inc., Boca Raton, Floride, 233 pp.

39. Dale C., Welburn S.C. \& Crampton J.M. (1994). - Transgenic tsetse flies: a future vector control strategy? In Proc. 22nd Meeting of the International Scientific Council for Trypanosomiasis Research and Control. Organisation de l'Unité africaine, Kampala, Ouganda, 1993 (sous presse).

40. Dame D.A. \& Ford H.R. (1966). - Effect of the chemosterilisant tepa on Glossina morsitans Westw. Bull. entomol. Res., 56 (2), 649-658.

41. DAme D.A. \& Schmidt C.H. (1970). - The sterile male technique against tsetse flies, Glossina spp. Bull. entomol. Soc. Am., 16,24-30. 
42. Darrow D.I., GladNEY W.J. \& Dawkins C.C. (1976). - Lone star tick: mating behavior of gamma-irradiated males. Ann. entomol. Soc. Am., 69, 106-108.

43. De Barjac H. \& Sutherland D.J. (1990). - Bacterial control of mosquitoes and black flies. Biochemistry, genetics and applications of Bacillus thuringiensis israelensis and Bacillus sphaericus. Unwin Hyman, Londres, $349 \mathrm{pp}$.

44. Douati A., Mehlitz D. \& Menninger R. (1993). - Glossina (Glossinidae: Diptera) control in savanna regions of Ivory Coast: Tsetse population and trypanosomiasis infection reduction. In Proc. 22nd Meeting of the International Scientific Council for Trypanosomiasis Research and Control. Organisation de l'Unité africaine, Kampala, Ouganda, 1993 (sous presse).

45. Drummond J., Miller D.K. \& Pinnock D.E. (1992). - Toxicity of Bacillus thuringiensis against Damalinia ovis (Phthiraptera: Mallophaga). J. Invertebr. Pathol., 60, 102-103.

46. Drummond R.O., Medley J.G. \& Graham O.H. (1966). - Engorgement and reproduction of lone star ticks (Amblyomma americanum L.) treated with gamma radiation. Int. J. Radiat. Biol., 10, 183-188.

47. Dryden M.W. \& Rust M.K. (1994). - The cat flea: biology, ecology and control. Vet. Parasitol., 52, 1-19.

48. DunCAN P. \& CowTAN P. (1980). - An unusual choice of habitat helps Camargue horse to avoid blood-sucking horse flies. Biol. Behav., 5, 55-60.

49. Eagleson J.S., Thomson D.R., Scott P.G., Cramer L.G. \& Barrick R.A. (1993). Field trials to confirm the efficacy of ivermectin jetting fluid for control of blow fly strike in sheep. Vet. Parasitol., 51, 107-112.

50. EAsTon E.R. (1986). - The stable fly-management and control in South Dakota. Livestock Entomol., 5, 1-11.

51. Easton E.R. \& Catangui M.A. (1988). - Vinyl plastic cage design for single-mating experiments to chemosterilize the stable fly (Diptera: Muscidae) with bisazir. J. econ. Entomol., 81, 400-402.

52. FAO (ORganisation des Nations unies POUR L'ALimENTATION ET L'AGRiculture) (1987). - Manuel de lutte contre la mouche tsé-tsé. Volume 3 : Les méthodes de lutte et leurs effets secondaires (J.N. Pollock, édit). FAO, Rome, 151 pp.

53. FAO (ORgANisATION DES Nations unies POUR L'ALIMENTATION ET L'AGRICULTURE) (1990). - Manuel de lutte contre la lucilie bouchère Cochlyomyia hominivorax, Coquerel. FAO, Rome, $105 \mathrm{pp}$.

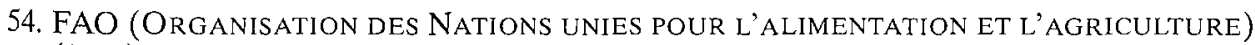
(1992). - The New World Screwworm Eradication Programme. North Africa, 1988-1992. FAO, Rome, $192 \mathrm{pp}$.

55. FAO (ORGANISATION DES NATIONS UNIES POUR L'ALIMENTATION ET L'AGRICULTURE) (1993). - Manuel de lutte contre la mouche tsé-tsé. Volume 4: Utilisation de dispositifs attractifs pour l'enquête et la lutte. FAO, Rome, $206 \mathrm{pp}$.

56. GaAfar S.M., Howaerd W.E. \& Marah R.E. (1985). - Parasites, pests and predators. World Animal Science, B2, Elsevier, Amsterdam, 591 pp.

57. Galun R., Warburg M. \& Avivi A. (1967). - Studies on the application of the sterility method in the tick Ornithodoros tholozani. Entomol. exp. Appl., 10, 143-152.

58. Gerberg E.J. (1985). - Sequential biocontrol application in the use of Toxorhynchites spp. In Integrated mosquito control methodologies, Vol. 2 (M. Laird \& J.J. Miles, édit.). Academic Press, Londres, 33-46. 
59. Gilles H.M. \& Warrell D.A. (1993). - Bruce-Chwatt's essential malariology, 3e éd. Edward Arnold, Londres, 340 pp.

60. Glazer I. \& Samith M. (1993). - Suitability of Boophilus annulatus replete female ticks as hosts of the nematodes Steinernema carpocapsae. J. Invertebr. Pathol, 61, 220-222.

61. GlofCheskie B.D. \& Surgeoner G.A. (1990). - Muscovy ducks as an adjunct for the control of the house fly (Diptera: Muscidae). J. econ. Entomol., 83, 788-791.

62. Greathead D.J. (1986). - Biological control of stable flies (Stomoxys calcitrans and S. nigra). Misc. Publ. entomol. Soc. Am., 61, 116-119.

63. Greenberg B. (1977). - Pathogens of Stomoxys calcitrans (stable fly). In Pathogens of medically important arthropods (D.W. Roberts \& M.A. Strand, édit.). Bull. Wld Hlth Org., 55, 259-261.

64. GREENE G.L. (1986). - Naturally-occurring parasites in six cattle feedlots near Garden City, Kansas. In Kansas Agricultural Experimental Station, Contribution No. 68-362D, 71-72.

65. GREENE G.L. (1990). - Biological control of filth flies in confined cattle feedlots using pteromalid parasites. In Biocontrol of arthropods affecting livestock and poultry (D.A. Rutz \& R.S. Patterson, édit.). Westview Press, Boulder, 29-42.

66. GREENE G.L. (1992). - Reduction of stable flies with adapted parasites and fly breeding site reduction. In Proc. of the XIX International Congress of Entomology (Abstracts), 28 juin-4 juillet, Beijing, Chine.

67. Greene G.L., Hogsette J.A. \& Patterson R.S. (1989). - Parasites that attack stable fly and house fly (Diptera: Muscidae) puparia during the winter on dairies in northwestern Florida. J. econ. Entomol., 82, 412-415.

68. Hall C.A., Martin I.C.A. \& MCDonnel P.A. (1980). - The effect of drying agent (B26) on wool moisture and blowfly strike. Res. vet. Sci., 29, 186-189.

69. Hall D.R., Gough A.J.E., Adams P.H., Beevor P.S., Cork A., Green C.H., Smith J.A., TAYLOR J.H.L. \& WARNES M.L. (1991). - Identification of host odour attractants for tsetse flies. Final report, 1986-1990. NRI/RTTCP, Chatham, Royaume-Uni, 130 pp.

70. Hargrove J.W. \& Langley P.A. (1993). - Sterilizing tsetse (Diptera: Glossinidae) in the field: a successful trial. Bull. entomol. Res., 80 (4), 397-403.

71. HARLEy K.L.S. \& Wilkinson P.R. (1964). - A comparison of cattle tick control by 'conventional' acaricidal treatment, planned dipping and pasture spelling. Aust. J. agr. Res., 15, 841-853.

72. HARLEY K.L.S. \& WILKINSON P.R. (1971). - A modification of pasture spelling to reduce acaricide treatments for cattle tick control. Aust. vet. J., 47, 108-111.

73. HARRIS W.G. \& BuRns E.C. (1977). - Predation of the lone star ticks by the imported fire ant. Environ. Entomol., $6(1), 362-365$.

74. Hassan S.M., Dipeolu O.O., Amoo A.O. \& OdhIAmbo T.R. (1991). - Predation on livestock ticks by chickens. Vet. Parasitol., 38, 199-204.

75. Hayakawa H., Tanaka K., Iwane K. \& Yamashita N. (1990). - A new tabanid fly trap with automatic $\mathrm{CO}_{2}$-emission apparatus run by weather sensors. Jpn. J. sanit. Zool, 41, 285-289.

76. Henderson G. \& Foil L.D. (1993). - Efficacy of diflubenzuron in simulated household and yard conditions against the cat flea Ctenocephalides felis (Siphonaptera: Pulicidae). $J$. med. Entomol., 30, 619-621. 
77. Hess E. \& De Castro J.J. (1986). - Field tests of the response of female Amblyomma variegatum (Acari: Ixodidae) to the synthetic aggregation-attachment pheromone and its components. Expl appl. Acarol., 2, 249-255.

78. Hink W.F., Drought D.C. \& BarnetT S. (1991). - Effect of an experimental systemic compound, CGA-186499, on life stages of the cat flea, Ctenocephalides felis (Siphonaptera: Pulicidae). J. med. Entomol., 28, 224-227.

79. HogsetTe J.A. \& RufF J.P. (1990). - Comparative attraction of four different fiberglass traps to various age and sex classes of stable fly (Diptera: Muscidae) adults. J. econ. Entomol., 83, 883-886.

80. Holloway M.T.P. \& Phelps R.J. (1991). - The responses of Stomoxys spp. (Diptera: Muscidae) to traps and artificial host odours in the field. Bull. entomol. Res., 81, 51-55.

81. Hribar L.J., LePrince D.J. \& Foll L.D. (1991). - Increasing horse fly (Diptera: Tabanidae) catch in canopy traps by reducing ultraviolet reflectance. J. med. Entomol., 26, 271-280.

82. HRibar L.J., LePrince D.J. \& Foll L.D. (1992). - Ammonia as an attractant for adult Hybomitra lasiophthalma (Diptera: Tabanidae). J. med. Entomol, 29, 346-348.

83. Huggert L. \& Morgan P.B. (1993). - Description and biology of Trichopria painterin. sp. (Hymenoptera: Diapriidae), a solitary parasitoid of Stomoxys calcitrans (Diptera: Muscidae) from Harare. Zimbabwe med. vet. Entomol., 7, 358-362.

84. Hugues P.B. \& Levot G.W. (1987). - Simulation of fly-waves to assess the ability of diflubenzuron to protect sheep against flystrike by Lucilia cuprina. Vet. Parasitol., 24 (3-4), 275-284.

85. ITARD J. (1971). - Elevage, cytogénétique et spermatogénèse des insectes du genre Glossina. Stérilisation des mâles par irradiation gamma. Ann. Parasitol., 46 (3 bis), 35-66.

86. Itard J. \& Bauer B. (1984). - Elevages de glossines. Synthèse. Rev. Elev. Méd. vét. Pays trop., 37 ( $\mathrm{N}^{\circ}$ spécial), 143-175.

87. JESPERSEN J.B. \& KEIDING J. (1990). - The effect of Bacillus thuringiensis var. thuringiensis on Musca domestica L. larvae resistant to insecticides. In Biocontrol of arthropods affecting livestock and poultry (D.A. Rutz \& R.S. Patterson, édit.). Westview Press, Boulder, 215-229.

88. JoHnson A.W. \& HAYs K.L. (1973). - Some predators of immature Tabanidae (Diptera) in Alabama. Environ. Entomol., 2 (6), 1116-1117.

89. Jones R.H., Luedke A.J., Walton T.E. \& MetCalf H.E. (1981). - Bluetongue in the United States - an entomological perspective toward control. World Anim. Rev., 38, 2-8.

90. Jordan A.M. (1986). - Trypanosomiasis control and African rural development. Longman Group Limited, Londres, $357 \mathrm{pp}$.

91. JurA W.G.Z.O. \& DAVIES-COLE J.O.A. (1992). - Some aspects of mating behaviour of Glossina morsitans morsitans males infected with a DNA virus. Biol. Contr, 2, 188-192.

92. KeTtLe D.S. (1984). - Medical and veterinary entomology. CAB International, Wallingford, Royaume-Uni, $658 \mathrm{pp}$.

93. KiENTZ A. (1992). - Prise en charge de la lutte anti-tsé-tsé par les bénéficiaires. Analyse exploratoire des opportunités et possibilités. GTZ, Eschborn, Allemagne, PN 87, 2539 , mars, 54 pp. et annexes.

94. KITAOKA S. \& MORII T. (1967). - Effects of gamma radiation and chemosterilants on the cattle tick Boophilus microplus (en japonais, résumé en anglais). Jpn. J. sanit. Zool., 18, 126-129. 
95. Klein K.K., Fleming C.S., Colwell D.D. \& SCholl P.J. (1990). - Economic analysis of an integrated approach to cattle grub (Hypoderma spp.) control. Can.J. Agric. Econ., 38, 159-173.

96. Kunz S.E., Scholl P.J., Colwell D.D. \& Weintraub J. (1990). - Use of sterile insect releases in an IPM program for control of Hypoderma lineatum and $H$. bovis (Diptera: Oestridae): a pilot test. J. med. Entomol., 27, 523-529.

97. Labrecque G.C.D., Meifert D.W. \& Rye J. (1972). - Experimental control of stable flies Stomoxys calcitrans (Diptera: Muscidae) by releases of chemosterilized adults. Can. Entomol., 104, 885-887.

98. LAIRD M. (1977). - Tsetse. The future for biological methods in integrated control. IDRC, Ottawa, $220 \mathrm{pp}$.

99. Lancaster J.L. \& Meisch M.V. (1986). - Arthopods in livestock and poultry production. Ellis Horwood Limited Publishers, Chichester, Royaume-Uni, 402 pp.

100. Langley P.A. \& Hall M.J.R. (1986). - Tsetse control by auto-sterilization. Parasitol. Today, $2,125$.

101. Larrouse F., King A.G. \& Wolbash S.B. (1928). - The overwintering in Massachusetts of Ixodiphagus caucurtei. Science, 67, 351-353.

102. LAVEISSIERE C. (1988). - Les glossines vectrices de la trypanosomiase humaine africaine. Biologie et contrôle. Série Lutte antivectorielle. Guide de formation et d'information. OMS/VBC/88-958, Genève, $91 \mathrm{pp}$.

103. LAVEissiere C. \& Grebaut P. (1990). - Recherches sur les pièges à glossines (Diptera : Glossinidae). Mise au point d'un modèle économique : le piège «Vavoua ». Trop. Med. Parasitol., 41, 185-192.

104. LEvin D.A. (1973). - The role of trichomes in plant defense. Quart. Rev. Biol., 48, 3-15.

105. LEvot G.W. (1993). - Insecticide resistance. New developments and future options for fly and lice control on sheep. Wool Tech. Sheep Breed., 41, 108-119.

106. LEVot G.W. \& ShIPp E. (1984). - Reduction in offspring survival of Lucilia cuprina (Wiedemann) following consumption of insect development inhibitors. J. Aust. entomol. Soc., 23, 85-89.

107. LONG D.W. \& FRENCH F.E. (1988). - Octenol as an olfactory stimulus to enhance trapping of horse flies (Tabanidae) in Malaise/flight traps and a fall diversity survey of tabanids. Georgia J. Sci., 16, 23-24.

108. Malonza M.M., Dipeolu O.O., Amoo A.O. \& Clatworthy J.N. (1992). - Laboratory and field observations on anti-tick properties of the plant Gynandropsis gynandra (L). Vet. Parasitol., 42, 123-136.

109. Mansour M.Y., Krafsur E.S. \& MuTchmor J.A. (1994). - Effects of anoxia during gamma irradiation on face fly fertility and viability (Diptera: Muscidae). $J$. med. Entomol., 31, 62-66.

110. Markwick N.P., Hill R.L. \& Allan D.J. (1989). - Muscidae, muscid flies (Diptera). In A review of biological control of invertebrate pests and weeds in New Zealand, 1870 to 1987 (P.J. Cameron, R.L. Hill, J. Bain \& W.P. Thomas, édit.). CAB International, Wallingford, Royaume-Uni, 387-394.

111. Mather T.N., Piesman J. \& Spielman A. (1987). - Absence of spirochaetes (Borrelia burgdorferi) and piroplasms (Babesia microti) in deer ticks (Ixodes dammini) parasitized by chalcid wasps (Hunterellus hookeri). Med. vet. Entomol., 1, 3-8.

112. Mauleon H., Barre N. \& Panoma S. (1993). - Pathogenicity of 17 isolates of entomophagous nematodes (Steinernematidae and Heterorhabditidae) for the ticks 
Amblyomma variegatum (Fabricius), Boophilus microplus (Canestrini) and Boophilus annulatus (Say). Expl appl. Acarol., 17, 831-838.

113. Meyer J.A., Mullens B.A., Cyr T.L. \& Stokes C. (1990). - Commercial and naturally occurring fly parasitoids (Hymenoptera: Pteromoidae) as biological control agents of stable flies and house flies (Diptera: Muscidae) on California Dairies. J. econ. Entomol., 83, 799-806.

114. Meyer J.A., Shultz T.A., Collar C. \& Mullens B.A. (1991). - Relative abundance of stable fly and house fly (Diptera: Muscidae) pupal parasites (Hymenoptera: Pteromalidae; Coleoptera: Staphylinidae) on confinement dairies in California. Environ. Entomol., 20, 915-921.

115. Mıнок S. (1994). - Trapping techniques for Stomoxys spp. In 22nd Meeting of the International Scientific Council for Trypanosomiasis Research and Control. Organisation de l'Unité africaine, Kampala, Ouganda, 1993 (sous presse).

116. Miller R.W. \& Pickens L.G. (1989). - Integrated pest management of house flies and stable flies on dairy farms. J. Dairy Sci., 67.

117. MiLne A. (1945). - The ecology of the sheep tick Ixodes ricinus L. The seasonal activity in Britain with particular reference to northern England. Parasitology, 36, 142-152.

118. Monty J. (1972). - A review of the stable fly problem in Mauritius. Rev. Agric. Suc. ile Maurice, 5, 13-29.

119. MonTy J. (1976). - Entomology Division. In Annual report. Ministère de l'Agriculture, Maurice, 49-78.

120. Moreau R.E. (1933). - The food of the redbilled oxpecker Buphagus erythrorhynchus (Stanley). Bull. entomol. Res, 24, 142-152.

121. Morel C. (1974). - Les méthodes de lutte contre les tiques en fonction de leur biologie. Cah. Méd. vét., 43, 3-23.

122. Morgan P.B. \& Patterson R.S. (1977). - Sustained release of Spalangia endius to parasitise field populations of three species of filth breeding flies. J. econ. Entomol., 70, 450-452.

123. Mount G.A. (1981). - Control of the lone star tick in Oklahoma parks through vegetative management. J. econ. Entomol., 74, 173-175.

124. Mwangi E.N., Dipeolu O.O., Newson R.M., KaAya G.P. \& Hassan S.M. (1991). Predators, parasitoids and pathogens of ticks: a review. Biocontr. Sci. Technol., 1, 147-156.

125. NEWSTEAd R. (1910). - Ticks and other blood-sucking Arthropoda of Jamaica. Bull. Dep. Agric. Jamaica, 1, 145-175.

126. Norton G.A., Sutherst R.W. \& MaYwald G.F. (1983). - A frame work for integrating control methods against the cattle tick, Boophilus microplus in Australia. J. Appl. Ecol., 20, 489-505.

127. Norval R.A.I. (1977). - Ecology of the tick Amblyomma hebraeum Koch in the eastern Cape Province of South Africa. I. Distribution and seasonal activity. J. Parasitol., 63, 734-739.

128. Norval R.A.I., Tebele N., Short N.J. \& Brig L. (1983). - A laboratory study on the control of economically important tick species with legumes of the genus Stylosanthes. Zimbabwe vet. J., 14, 26-29.

129. Norval R.A.I., Yunker C.E. \& ButLer J.F. (1987). - Field sampling of unfed adults of Amblyomma hebraeum Koch. Expl appl. Acarol., 3, 213-217. 
130. Norval R.A.I., Yunker C.E., Gibson J.D. \& DeEm S.L.D. (1988). - Field sampling of unfed nymphs of Amblyomma hebraeum. Expl appl. Acarol., 4, 173-177.

131. Norval R.A.I., Butler J.F. \& Yunker C.E. (1989). - Use of Carbon dioxide and natural or synthetic aggregation-attachment pheromone of the bont tick, Amblyomma hebraeum, to attract and trap unfed adults in the field. Expl appl. Acarol., 7, 171-180.

132. Norval R.A.I., Yunker C.E., Duncan I.M. \& Peter T. (1991). - Pheromone/acaricide mixtures in the control of the tick Amblyomma hebraeum: effects of acaricides on attraction and attachment. Expl appl. Acarol., 11, 233-240.

133. Norval R.A.I., Peter T., Yunker C.E., Sonenshine D.E. \& Burridge M.J. (1991). Responses of the ticks Amblyomma hebraeum and $A$. variegatum to known or potential components of the aggregation-attachment pheromone. I. Long-range attraction. Expl appl. Acarol., 13, 11-18.

134. Novy J.E. (1991). - Lutte contre la lucilie bouchère et éradication de cet insecte dans le sud des Etats-Unis. Rev. mond. Zootech., ( ${ }^{\circ}$ spécial), 18-27.

135. OlsEn A. (1984). - Methoprene, carpet cleaning and flea recruitment. In Danish Pest Infestation Laboratory, Annual Report of 1983, 59-60.

136. OlSEN A. (1990). - Flea biology. Danish Pest Infestation Laboratory, Annual Report of 1989,68 pp.

137. Omeara T.J., Nesa M., RaAdsma H.W., Saville D.G. \& Sandeman R.M. (1992). Variation in skin inflammatory responses beween sheep bred for resistance or susceptibility to fleece rot and blowfly strike. Res. vet. Sci., 52, 205-210.

138. OMS (ORGANISATION MONDIALE DE LA SANTÉ) (1980), - La lutte antivectorielle par l'aménagement de l'environnement. Série de Rapports techniques $\mathrm{N}^{\circ} 649$. OMS, Genève, 79 pp.

139. Osbrink W.L.A. \& Rust M.K. (1968). - Distribution and control of cat fleas in homes in southern California (Siphonaptera: Pulicidae). J. econ. Entomol., 79, 135-140.

140. OsBuRn R.H. \& KNIPLING E.F. (1982). - The potential use of sterile hybrid Boophilus ticks (Acari: Ixodidae) as a supplemental eradication technique. J. med. Entomol., 19, 637-142.

141. PARMAN D.C. (1928). - Experimental dissemination of the tabanid egg parasite Pharnurus emersoni Girault and biological notes on the species. USDA Circular, 18, 1-6.

142. Patterson R.S., Labrecoue G.C. \& Williams D.F. (1980). - Use of the sterile-male technique as an adjunct to insecticidal and physical methods for stable fly control on the Island of St-Croix, USVI. In International Symposium on the use of isotopes for research and control of animal diseases, host pathogen relationships and the environmental impact of control procedures, Vienne, Autriche, 7-11 mai 1979. AIEA, Vienne, 283-295.

143. Patterson R.S., Labrecque G.C., Williams D.F. \& WeidhaAs D.E. (1981). - Control of the stable fly, Stomoxys calcitrans (Diptera: Muscidae), on St Croix, U.S. Virgin Islands, using integrated pest management measures. III. Field techniques and population control. J. med. Entomol., 18, 203-210.

144. Pavis C., Mauleon H., Barre N. \& Maibeche M. (1994). - Cuticular secretions of the tropical bont tick, Amblyomma variegatum (Acarina: Ixodidae): effects on predators and pathogens. J. Chem. Ecol. (sous presse).

145. Petersen J.J. (1989). - Potential for biological control of stable flies associated with confined livestock. Current status of stable fly (Diptera: Muscidae) research. In Proceedings of a symposium preserited at the National Conference of the Entomological Society of America (J.J. Petersen \& J.J. Greene, édit.). Misc. Publ. entomol. Soc. Am., 74, 41-45. 
146. PICKENS L.G. (1989). - Relative attractiveness of paired BL and BLB fluorescent bulbs for house and stable flies (Diptera: Muscidae). J. econ. Entomol., 82, 535-538.

147. PiCKENS L.G. (1991). - Battery-powered, electrocuting trap for stable flies (Diptera: Muscidae). J. med. Entomol., 28, 822-830.

148. PiCKENS L.G. \& Mills G.D. (1993). - Solar-powered electrocuting trap for controlling house-flies and stable flies (Diptera: Muscidae). J. med. Entomol., 30, 872-877.

149. Politzar H. \& Cuisance D. (1984). - An integrated campaign against riverine tsetse Glossina palpalis gambiensis and Glossina tachinoides by trapping and the release of sterile males. Insect Sci. Applic., 5, 439-442.

150. Portman R.W. (1945). - Pasture management kills lone star ticks. Circ. Missouri agric. Exp. Stat., 297, 4 pp.

151. Purnell R.E., Dargie J.D., Gilliver B., Irvin A.D. \& Ledger M.A. (1972). - Some effects of irradiation on the tick Rhipicephalus appendiculatus. Parasitology, 64, 429-440.

152. Quelennec G., Simonkovich E. \& Ovazza M. (1968). - Recherche d'un type de déversoir de barrage défavorable à l'implantation de Simulium damnosum (Diptera : Simulidae). Bull. OMS, 38, 943-956.

153. Rajagopalan P.K., Das P.K., Panicker K.N., Reuben R., Rao D.R., Self L.S. \& Lines D.J. (1990). - Environmental and water management for mosquito control. In Appropriate technology in vector control (C.F. Curtis, édit.). CRC Press Inc., Boca Raton, Floride, 121-138.

154. Raymond H.L. (1978). - Contribution à l'étude des Tabanidae (Diptera) de Camargue. Terre \& Vie, 32, 291-303.

155. Raymond H.L. (1979). - Premières observations sur les ennemis naturels des Tabanidae (Diptera) des Hautes-Alpes. Ann. Zool. Ecol. anim., 11, 355-358.

156. RAYMOND H.L. (1988). - Abondance relative et dynamique saisonnière des Tabanidae (Diptera) d'une savane de Guyane française. Naturaliste can., 115, 251-259.

157. RAYMOND H.L. (1989). - Biologie des mouches-lézards, guêpes Bembicines de Guyane française (Hym. Sphecidae). Bull. Soc. Entomol. Fr., 93, 301-308.

158. RAYMOND H.L. (1989). - Distribution temporelle des principales espèces de taons (Diptera : Tabanidae) nuisibles au bétail en Guyane française. Ann. Soc. Entomol Fr. (N.S.), 25, 289-294.

159. Raymond H.L. (1991). - Rôle et limites des ennemis naturels des taons (Diptera : Tabanidae) : le cas des mouches-lézards en Guyane française. In Rencontres Caraïbes en lutte biologique, Guadeloupe (Antilles françaises), 5-7 novembre 1990. INRA, 236-245.

160. RaYMond H.L., BARRE N. \& Camus E. (1987). - Données nouvelles sur les taons (Diptera : Tabanidae) et les tiques (Acari : Ixodidae) de Guyane française. In Systèmes d'élevage herbager en milieu équatorial. Colloque INRA, CIRAD, ORSTOM, Cayenne, 9-10 décembre 1985. INRA, Paris, 321-334.

161. Rechav Y., Norval R.A.I. \& Oliver J.H. (1982). - Interspecific mating of Amblyomma hebraeum and Amblyomma variegatum (Acari: Ixodidae). J. med. Entomol., 19, 139-142.

162. Reuben R., Rao D.R., Sebastian A., Corbet P.S., Neng W. \& Guohou L. (1990). Biological control methods suitable for community use. In Appropriate technology in vector control (C.F. Curtis, édit.). CRC Press Inc., Boca Raton, Floride, 139-158. 
163. RobeRTS L.W. \& WiLSON B.H. (1967). - Predation of horse flies by two bembicine wasp species in certain areas of Southern Louisiana J. econ. Entomol., 60, 412-415.

164. RoberTs R.H. (1975). - Relationship between the amount of $\mathrm{CO}_{2}$ and the collection of Tabanidae in Malaise traps. Mosq. News, 35, 150-154.

165. RoBERTS R.H. (1976). - The comparative efficiency of six trap types for the collection of Tabanidae (Diptera). Mosq. News, 36, 530-535.

166. Rodhain F. \& Perez C. (1985). - Les taons : systématique, biologie, importance médicale. In Précis d'entomologie médicale et vétérinaire. Notions d'épidémiologie des maladies à vecteurs. Maloine, Paris, $458 \mathrm{pp}$.

167. Rodriguez J., Villalba G., Abreu R. \& Castineiras A. (1983). - Pheidole megacephala (Hymenoptera: Formicidae) como depredador de Amblyomma cajennense (Acarina: Ixodidae) en Cuba. Revta Salud Anim., 5, 437-440.

168. Rutz D.A. \& PatTerson R.S. (1990). - Biocontrol of arthropods affecting livestock and poultry (D.A. Rutz \& R.S. Patterson, édit.). Westview Press Inc., Boulder, Colorado, $316 \mathrm{pp}$.

169. Samish M. \& Glazer I. (1992). - Infectivity of entomopathogenic nematodes (Steinernematidae and Heterorhabditidae) to female ticks of Boophilus annulatus (Arachnida: Ixodidae). J. med. Entomol., 29, 614-618.

170. Saubenova O.G. \& Levchenko N.G. (1975). - Détection du champignon Metarhizium anisopliae (Metsch.) Sorokin (Deutéromycètes, Moniliales) chez les larves et les nymphes des taons du Kazakhstan (en russe). Med. Parazit., 44, 733-735.

171. SCHMIDTMANN E.T. (1988). - Exploitation of bedding in dairy outdoor calf hutches by immature house and stable flies (Diptera: Muscidae). J. med. Entomol., 25, 484-488.

172. Schöni R., Hess E., Blum W. \& Ramstein K. (1984). - The aggregation-attachment pheromone of the tropical bont tick Amblyomma variegatum Fabricius (Acari: Ixodidae). Isolation, identification and action of its components. J. Insect Physiol., 30, 613-618.

173. Schreck C.E., KLIne D.L., Wilsons D.C. \& Tidwell M.A. (1993). - Field evaluations in Malaise and canopy traps of selected targets as attractants for tabanid species (Diptera: Tabanidae). J. Am. Mosq. Contr. Assoc., 9, 182-188.

174. Smith C.N. \& Cole M.M. (1943). - Studies of parasites of the American dog tick. J. econ. Entomol., 36, 569-572.

175. SMrTH L. \& RuTz D.A. (1991). - Seasonal and relative abundance of hymenopterous parasitoids attacking house fly pupae at dairy farms in central New York. Environ. Entomol., 20, 661-668.

176. SMith M.W. (1975). - Some aspects of the ecology and lifecycle of Amblyomma cajennense (Fabricius 1787) in Trinidad and their influence on tick control measures. Ann. trop. Med. Parasitol., 69, 121-129.

177. SPICKETT A.M. (1978). - Effects of ${ }^{60}$ Co irradiation on Amblyomma hebraeum Koch, 1844 (Acarina: Ixodidae). Onderstepoort J. vet. Res., 45 (3), 197-201.

178. SPICKETT A.M. (1987). - The natural control of heartwater vectors. Onderstepoort J. vet. Res., 54, 535-539.

179. Spickett A.M. \& Malan J.R. (1978). - Genetic incompatibility between Boophilus decoloratus (Koch, 1844) and Boophilus microplus (Canestrini, 1888) and hybrid sterility of Australian and South African Boophilus microplus (Acarina: Ixodidae). Onderstepoort J. vet. Res., 45, 149-153. 
180. Sutherst R.W. (1987). - The dynamics of hybrid zones between tick species. Int. J. Parasitol., 17, 921-926.

181. Sutherst R.W., Dallwitz M.J., Utech K.B.W. \& KerR J.D. (1977). - Aspects of host finding by the cattle tick, Boophilus microplus. Aust. J. Zool., 25, 159-174.

182. Sutherst R.W., Wharton R.H. \& UTECH K.B.W. (1978). - Guide to studies on tick ecology. Division of Entomology, Technical paper no. 14. CSIRO, Australia, $59 \mathrm{pp}$.

183. Sutherst R.W., Jones R.J. \& Schnitzerling H.J. (1982). - Tropical legumes of the genus Stylosanthes immobilize and kill cattle ticks. Nature, 295, 320-321.

184. Takken W., Oladunmade M.A., Deng L., Feldmann U., Onah J.A., Tenabe S.O. \& HAMANN H.J. (1986). - The eradication of Glossina palpalis palpalis (Robineau Desvoidy) (Diptera: Glossinidae) using traps, insecticide-impregnated targets and the sterile insect technique in central Nigeria. Bull. entomol. Res., 76, 275-286.

185. Thompson G.D., Osburn R.L., Davey R.B. \& Price M.A. (1981). - The dynamics of hybrid sterility between Boophilus annulatus and B. microplus (Acari: Ixodidae) through successive generations. J. med. Entomol., 18, 413-418.

186. Thompson J.W., Mitchell M., Rees R.B., Shereni W., Schoenfeld A.H. \& Wilson A. (1991). - Studies on the efficacy of deltamethrin applied to cattle for the control of tsetse flies (Glossina spp.) in Southern Africa. Trop. Anim. Hlth Prod., 23 (4), 221-226.

187. Thompson K.C., RoA J. \& Romeo S. (1978). - Anti-tick grasses as the basis for developing practical tropical tick control packages. Trop. Anim. Hlth Prod., 10, 179-182.

188. TORR S.J. \& HALl M.J.R. (1992). - Odour-baited targets to control New World screwworm, Cochliomyia hominivorax (Diptera: Calliphoridae): a preliminary study. Bull. entomol. Res., 82 (3), 417-423.

189. Urquhart G.M., Armour J., Duncan J.L., Dunn A.M. \& Jennings J.W. (1987). Veterinary parasitology. Longman Scientific and Technical, Londres, $286 \mathrm{pp}$.

190. VALE G.A. (1980). - Field studies of the responses of tsetse flies (Glossinidae) and other Diptera to carbon dioxide, acetone and other chemicals. Bull. entomol. Res., 70, 563-570.

191. VALE G.A. (1993). - Development of baits for tsetse flies (Diptera: Glossinidae) in Zimbabwe. J. med. Entomol., 30 (5), 831-842.

192. Vale G.A. \& Hargrove W. (1979). - A method of studying the efficiency of traps for tsetse flies (Diptera: Glossinidae) and other insects. Bull. entomol. Res., 69, 183-193.

193. VAle G.A., Lovemore D.F., FlinT S. \& Cockbill G.F. (1988). - Odour-baited targets to control tsetse flies, Glossina sp. (Diptera: Glossinidae) in Zimbabwe. Bull. entomol. Res., 78, 31-49.

194. WALker J.B., Norval R.A.I. \& CoRWIN M.D. (1981). - Rhipicephalus zambeziensis sp. nov., a new tick from eastern and southern Africa, together with a redescription of Rhipicephalus appendiculatus Neumann, 1901 (Acarina: Ixodidae). Onderstepoort J. vet. Res., 48, 87-104.

195. Wall R., Green C.H., French N. \& Morgan K.L. (1992). - Development of an attractive target for the sheep blowfly Lucilia sericata. Med. vet. Entomol., 6, 67-74.

196. Watson D.W. \& Petersen J.J. (1991). - Infectivity of Serratia marcescens (Eubacteriales: Enterobacteriaceae) in Stomoxys calcitrans (Diptera: Muscidae). J. med. Entomol., 28, 190-192.

197. Wharton R.H., HARLEy K.L.S., Wilkinson P.R., Utech K.B. \& KElley B.M. (1969). A comparison of cattle tick control by pasture spelling, planned dipping and tickresistant cattle. Aust. J. agric. Res., 20, 783-797. 
198. Wilkinson P.R. (1957). - The spelling of pasture in cattle tick control. Aust. J. agric. Res., 8, 414-423.

199. WILKINSON P.R. (1970). - Factors affecting the distribution and abundance of the cattle tick in Australia. Acarologia, 12, 492-507.

200. WiLkINSON P.R. (1979), - Ecological aspects of pest management of ixodid ticks. Rec. Adv. Acarol., 2, 25-33.

201. WiLliams D.F. (1973). - Sticky traps for sampling populations of Stomoxys calcitrans. J. econ. Entomol., 66, 1279-1280.

202. Williams D.F., Skov O. \& Patterson R.S. (1977). - Two traps for collecting live stable flies Stomoxys calcitrans (L.) in the field. Mosq. News, 37, 404-406.

203. Williamson D.L., Dame D.A., Gates D.B., Cobb P.E., Bakuli B. \& Warner P.V. (1983). - Integration of insect sterility and insecticides for control of Glossina morsitans morsitans Westwood (Diptera: Glossinidae) in Tanzania. V. The impact of sequential releases of sterilized tsetse flies. Bull. entomol. Res., 73, 391-404.

204. Wills L.E., Mullens B.A. \& MANDEVIlLE J.D. (1990). - Effects of pesticides on filth fly predators (Coleoptera: Histeridae, Staphylinidae; Acarina; Macrochelidae, Uropodidae) in caged layer poultry manure. J. econ. Entomol., 83, 451-457.

205. Wilson B.H., Tugwell N.P. \& BuRns E.C. (1966). - Attraction of tabanids to traps baited with dry ice under field conditions in Louisiana. J. med. Entomol, 3, 148-149.

206. Yunker C.E., Peter T., Norval R.A.I., Sonenshine D.E., Burridge M.J. \& Butler J.F. (1992). - Olfactory responses of adult Amblyomma hebraeum and A. variegatum (Acari: Ixodidae) to attractant chemicals in laboratory tests. Expl appl. Acarol., 13, 295-301.

207. Zimmerman R.H., Garris G.I. \& Beaver J.S. (1984). - Potential of Stylosanthes plants as a component in an integrated pest management approach to tick control. Prev. vet. Med., 2, 579-588. 